\title{
A well conserved archaeal B-family polymerase functions as a mismatch and lesion extender
}

1 Xu Feng ${ }^{1}$, Baochang Zhang ${ }^{1}$, Zhe Gao ${ }^{1}$, Ruyi Xu ${ }^{1}$, Xiaotong Liu ${ }^{1}$, Sonoko Ishino ${ }^{2}$, Mingxia 2 Feng ${ }^{1}$, Yulong Shen ${ }^{1}$, Yoshizumi Ishino ${ }^{2}$ and Qunxin She ${ }^{1 *}$

$3 \quad{ }^{1}$ CRISPR and Archaea Biology Research Center, Microbial Technology Institute and State Key 4 Laboratory of Microbial Technology, Shandong University, Qingdao, P.R. China

$5 \quad 2$ Department of Bioscience and Biotechnology, Graduate School of Bioresource and

6 Bioenvironmental Sciences, Kyushu University, Fukuoka, Japan

8 * Correspondence:

9 Qunxin She

10 shequnxin@sdu.edu.cn

11 Keywords: Sulfolobus, DNA polymerase ${ }_{2}$, Dpo2 $_{3}$, Translesion DNA synthesis 4 , Archaea, 12 lesion extender, 6 , Mismatch extension 7.

13 The manuscript contains 4 figures and 2 tables. 


\section{ABSTRACT}

16 B-family DNA polymerases (PolBs) of different groups are widespread in Archaea and different 17 PolBs often coexist in the same organism. Many of these PolB enzymes remain to be investigated. 18 One of the main groups that are poorly characterized is PolB2 whose members occur in many 19 archaea but are predicted as an inactivated form of DNA polymerase. Herein, Sulfolobus islandicus 20 DNA polymerase 2 (Dpo2), a PolB2 enzyme was expressed in its native host and purified. 21 Characterization of the purified enzyme revealed that the polymerase harbors a robust nucleotide 22 incorporation activity, but devoid of the 3'-5' exonuclease activity. Enzyme kinetics analyses 23 showed that Dpo2 replicates undamaged DNA templates with high fidelity, which is consistent with 24 its inefficient nucleotide insertion activity opposite different DNA lesions. Strikingly, the 25 polymerase is highly efficient in extending mismatches and mispaired primer termini once a 26 nucleotide is placed opposite a damaged site. Together, these data suggested Dpo2 functions as a 27 mismatch and lesion extender, representing a novel type of PolB that is primarily involved in DNA 28 damage repair in Archaea. Insights were also gained into the functional adaptation of the motif $\mathrm{C}$ 29 in the mismatch extension of the B-family DNA polymerases. 


\section{INTRODUCTION}

Cellular organisms code for multiple DNA polymerases that play crucial roles in the chromosome duplication and the genome integrity maintenance during the normal growth and under stressed conditions. Eight different families of DNA polymerases (pols) are known based on their amino acid sequences, and as many as 17 DNA pols are encoded in human [1]. Some polymerases are devoted to chromosome replication (replicase) while others are specialized for DNA damage repair. Bacterial replicases for chromosome replication are of the C-family, and those in the organisms of Eukarya and Archaea belong to the B-family or D-family [2; 3; 4]. Replicative polymerases possess both the polymerase and exonuclease domains and replicate undamaged DNA with high fidelity and processivity. In contrast, most specialized DNA pols are of X- and Y-family. These pols are often devoid of any proof-reading activity and replicate DNA with reduced fidelity and processivity [1]. A noticeable exception of specialized pols is the eukaryotic Pol $\zeta$, a B-family DNA polymerase, which plays important role in the eukaryotic translesion DNA synthesis (TLS) by functioning as a mismatch and lesion extender.

Sulfolobales organisms code for four DNA polymerases such as Sulfolobus islandicus, Sulfolobus acidocaldarius and Saccharolobus solfataricus P2 (formerly Sulfolobus solfataricus). These DNA pols were initially named as Dpo1, Dpo2, Dpo3 and Dpo4/Dbh among which the first three belong to the B family (also known as PolB1, PolB2 and PolB3) whereas the last is a Y-family pol $[5 ; 6 ; 7]$. DNA pols encoded in $S$. solfataricus were characterized in vitro in different research laboratories, and these analyses have revealed the Dpo1 and Dpo3 enzymes are high-fidelity DNA polymerases exhibiting the 3' -5 ' exonuclease activity, and this is consistent with their predicted function in the processive DNA replication in this crenarchaeon $[8 ; 9 ; 10]$. The S. solfataricus Dpo4 represents the most extensively characterized Y-family DNA pol. This enzyme is capable of bypassing various DNA lesions $[11 ; 12 ; 13 ; 14]$, suggesting it could be responsible for the translesion synthesis in this organism. However, the encoding gene does not show any DNA damage-inducible expression in all tested Sulfolobales organisms, including $S$. acidocaldarius, $S$. solfataricus, and $S$. islandicus $[15 ; 16 ; 17 ; 18 ; 19]$, and it does not play a role in the targeted mutagenesis as we have demonstrated with the $S$. islandicus $\Delta d p o 4$ mutant [20]. The only DNA pol gene that does show the damage-inducible expression is $d p o 2$ coding for a PolB2 enzyme [15; 16], and it has been further shown that $d p o 2$ is solely responsible for the DNA damage-induced mutagenesis in S. islandicus [20]. Nevertheless, members of the PolB2 subfamily were regarded as inactive polymerases since they carry amino acid substitutions at the catalytic center [21]. Consequently, whether Dpo 2 could be an active polymerase represents very important question in the TLS study in Dpo2-encoding organisms, and if so, it would be intriguing to know how this unique DNA pol could contribute to DNA damage repair in these archaea.

Herein, we biochemically characterized the $S$. islandicus Dpo2. Recombinant Dpo2 protein was obtained from the native host and investigated for its capability of DNA polymerization, proofreading and lesion bypass. We found that Dpo2 is a robust DNA pol in nucleotide incorporation but devoid of the 3'-5' exonuclease activity. This unique DNA pol replicates undamaged DNA with a high replication fidelity that is comparable to that of Dpo1, the main replicase of the organism. We further demonstrate that Dpo2 is very efficient in extension of mismatched primer termini as well as primer termini opposite to DNA lesions. Together, these results indicated that the PolB2 enzymes are specialized DNA polymerases that can play very important roles in archaeal DNA damage repair.

\section{MATERIALS AND METHODS}

\section{Sulfolobus strains and growth conditions}


S. islandicus E233S ( $\triangle p y r E F \Delta l a c S$ ) [22], derived from S. islandicus REY15A, the wild-type strain [23], was employed as the host for expression of recombinant DNA polymerases including $S$. islandicus Dpo2 and Dpo1, and S. solfataricus Dpo2. Sulfolobus strains were grown in SCV $(0.2 \%$ sucrose, $0.2 \%$ casamino acids, $1 \%$ vitamin solution plus basic salts) or ACV media $(0.2 \%$ Darabinose, $0.2 \%$ casamino acids, $1 \%$ vitamin solution plus basic salts) at $78^{\circ} \mathrm{C}$ as previously described [24].

\section{Expression and purification of DNA polymerases from $S$. islandicus}

The $S$. islandicus Dpo2-expression plasmid and its native host strain were constructed previously [25]. Dpo1 (SiRe_1451) and SsoDpo2 (Sso1459) encoding genes were amplified by PCR using corresponding oligos listed in Supplementary Table S1 and individually cloned into pSeSD, an arabinose inducible expression vector [24]. Construction of the expression plasmids, expression of the DNA pol genes and purification of the encoded proteins from $S$. islandicus E233S were conducted as previously described [26]. Briefly, 20-500 ng plasmid DNA were used for electroporation transformation for each plasmid, and the colonies appeared on the selective plates (SCV) were check for DNA insert by colony PCR, and the target genes were verified by sequencing of the PCR product. Transformants carrying each expression plasmid were firstly cultured in SCV, the non-induction medium, for cell growth. Then, the cultures were transferred into ACV, the induction medium, for protein expression. Cell mass was harvested from ca. $11 \mathrm{~L}$ of ACV cultures and used for the purification of Dpo2 and Dpo1 individually by the following procedures. Cell pellets were resuspended in Buffer A (50 mM Tris- $\mathrm{HCl}, 200 \mathrm{mM} \mathrm{NaCl}, 30 \mathrm{mM}$ Imidazole, $\mathrm{pH}$ 7.5) supplemented with $1 \mathrm{x}$ protease inhibitor cocktails and $10 \mu \mathrm{g} / \mathrm{ml}$ DNase I. Cell lysates were obtained by passing the cell suspension through a high-pressure homogenizer (JNBIO). Cell debris in the lysates were removed by centrifugation at $15000 \mathrm{xg}$ for $40 \mathrm{~min}$ and the supernatant was filtered through a $0.45 \mu \mathrm{m}$ filter. The clarified supernatant was then applied to a Histrap HP column (Cytiva) and the target protein bound to the Ni column via the specific His tag-Ni ion interaction was then eluted with Buffer B $(50 \mathrm{mM}$ Tris- $\mathrm{HCl}, 200 \mathrm{mM} \mathrm{NaCl}, 500 \mathrm{mM}$ Imidazole, $\mathrm{pH}$ 7.5). Further purification of recombinant protein was different for Dpo2 and Dpo1. In the case of Dpo2, pooled fractions were diluted using Buffer $\mathrm{C}(20 \mathrm{mM}$ Tris- $\mathrm{HCl}, \mathrm{pH} 8.0)$, and applied onto a Heparin HP column (Cytiva). Proteins bound to the Heparin column were then eluted by a linear gradient of buffer D (20 mM Tris-HCl, $1 \mathrm{M} \mathrm{NaCl}, \mathrm{pH} 8.0)$ over a $25 \mathrm{x}$ column volume. Further purification of Dpo1 was conducted by size exclusion chromatography with a Superdex 200 increase 10/300 GL column (Cytiva). Fractions containing each DNA pol of a high purity were pooled and concentrated using a $10 \mathrm{~K}$ protein concentrator (Millipore). Concentrated proteins were preserved at $-20{ }^{\circ} \mathrm{C}$ in the presence of $50 \%$ glycerol. The concentration of each protein was determined using Bradford assay [27], with BSA of known concentrations as standards.

\section{DNA substrates}

All synthetic oligos including unlabeled, FAM-labeled primers, undamaged templates, and templates containing base modifications were synthesized and purified by HPLC at Genewiz (Suzhou, CN) or Sangon Biotech (Shanghai, CN). The exception was a CPD-containing oligo, which was synthesized and purified by Gene Link (Elmsford, NY, USA). The sequence of primers and templates were listed in Supplementary Table S1. DNA substrates were prepared by annealing corresponding primer stand and template strand at 1:1.5 ratio using a thermal cycler, in which the temperature was decreased by $0.2{ }^{\circ} \mathrm{C}$ each cycle for 350 cycles after denaturation at $95{ }^{\circ} \mathrm{C}$ for 5 min.

\section{Optimization of reaction conditions}


The optimal $\mathrm{pH}$ was determined using Bis-Tris based buffer system in the $\mathrm{pH}$ range of 6.0-7.2 and Tris- $\mathrm{HCl}$ system in the range of 6.8-8.8. Salt concentrations of $\mathrm{NaCl}$ and $\mathrm{KCl}$ were screened at the $\mathrm{pH} 8.0$ of Tris- $\mathrm{HCl}$ buffer. At optimal $\mathrm{pH}$ and salt concentration, the reaction temperature and concentration of metal ions was optimized. From these experiments, the optimal condition was determined for the Dpo2 reaction in the solution containing $50 \mathrm{mM}$ Tris- $\mathrm{HCl}(\mathrm{pH} 8.0), 40 \mathrm{mM} \mathrm{KCl}$, $10 \mathrm{mM} \mathrm{MgCl}, 0.1 \mathrm{mg} / \mathrm{mL}$ BSA, at $60{ }^{\circ} \mathrm{C}$, and it was used for the following analyses.

\section{Primer extension assay}

Primer extension was set up in a $10 \mu \mathrm{l}$ reaction system containing $50 \mathrm{nM}$ substrates, DNA polymerases with indicated concentrations, $100 \mu \mathrm{M}$ of either all four dNTPS or each dNTP individually, $50 \mathrm{mM}$ Tris- $\mathrm{HCl}(\mathrm{pH} 8.0), 40 \mathrm{mM} \mathrm{KCl}, 10 \mathrm{mM} \mathrm{MgCl}, 0.1 \mathrm{mg} / \mathrm{mL}$ BSA using undamaged or damaged templates. The assay was carried out at $60{ }^{\circ} \mathrm{C}$ for $10 \mathrm{~min}$ or with the time periods indicated in each experiment. The reaction was terminated by addition of $10 \mu 12 \mathrm{x}$ loading dye solution (1x TBE, $8 \mathrm{M}$ Urea, $10 \mathrm{mM}$ EDTA, 0.1\% bromophenol blue), followed by denaturation at $95{ }^{\circ} \mathrm{C}$ for $5 \mathrm{~min}$ and immediate chilling on ice. Replication products were resolved by $18 \%$ urea polyacrylamide gel electrophoresis and visualized by an Amersham ImageQuant 800 biomolecular imager (Cytiva).

\section{Proofreading assay}

The assay was performed essentially as described in primer extension assay, except dNTPs were omitted from the reaction.

\section{Steady-state kinetics analysis}

Steady state kinetics was performed as described [28]. To ensure that the reaction was in the linear range, products formation was kept to less than $20 \%$ of the starting substrate. For misincorporation and mismatch extension kinetic assay, each $10 \mu \mathrm{l}$ reaction contained $50 \mathrm{nM} 5$, FAM-labelled substrate, $1000 \mathrm{nM}$ corresponding unlabeled cold DNA substrate with the same DNA sequence, $350 \mathrm{nM}$ Dpo2 protein. The reaction was initiated by addition of dNTP with varying concentrations and was terminated by mixing with $10 \mu 12 \mathrm{x}$ loading dye solution (1x TBE, $8 \mathrm{M}$ urea, $10 \mathrm{mM}$ EDTA and $0.03 \%$ bromophenol blue) and heating at $95{ }^{\circ} \mathrm{C}$ for $5 \mathrm{~min}$. Products were resolved in a $18 \%$ urea-PAGE gel and visualized by an Amersham ImageQuant 800 biomolecular imager. The percentage of products formation was quantitated using ImageQuant software and the velocity of dNTP incorporation was calculated by dividing the yield of products formed by the respective time of the reaction at each concentration of dNTP. The data was fitted into Michaelis-Menton equation using Graphpad prism software, from which the apparent $\mathrm{K}_{\mathrm{cat}}$ and $\mathrm{K}_{\mathrm{m}}$ values were determined. The misinsertion frequency was expressed as $f_{\text {inc }}=\left(\mathrm{K}_{\text {cat }} / \mathrm{K}_{\mathrm{m}}\right)$ incorrect $/\left(\mathrm{k}_{\mathrm{cat}} / \mathrm{K}_{\mathrm{m}}\right)$ correct. The intrinsic efficiency of mismatch extension of Dpo2 on mismatch extension was calculated as described [29] using the equation: $f_{\text {ext }}^{0}=\left(\mathrm{K}_{\mathrm{cat}} / \mathrm{K}_{\mathrm{m}}\right)_{\text {mismatch }} /\left(\mathrm{K}_{\mathrm{cat}} / \mathrm{K}_{\mathrm{m}}\right)_{\text {matched, which measures the relative probability }}$ of extending mismatched termini in competition with matched primer, in the limit of zero next nucleotide and has been widely used to evaluate the mispair extension ability of DNA polymerases $[29 ; 30 ; 31]$. The substrates used for misincorporation kinetics including P2-T1, P2-T1-A, P2-T1G$\mathrm{A}$ and P2-T1C as indicated in Supplementary Table S2. The substrates used for mismatch extension kinetics including P3-T1N (N=A, T, G or C), P3T-T1N (N=A, T, G or C), P3G-T1N (N=A, T, G or C) and P3C-T1N (N=A, T, G or C).

\section{RESULTS}

\section{S. islandicus Dpo2 is an active DNA polymerase devoid of the exonuclease activity}


In a previous work, we showed that $d p o 2$ is the only DNA polymerase gene essential for DNA damage-induced mutagenesis in $S$. islandicus [20]. To test how this polymerase could be related to other B-family DNA polymerases, multiple sequence alignments were conducted for the $S$. islandicus Dpo2 protein together with a selected set of B-family polymerases, including those of Saccharomyces cerevisiae, E. coli and a few archaea. This analysis revealed that the PolB2 enzymes from different archaeal species possess a relatively conserved polymerase domain, including conserved PolA, PolB and PolC motifs that are normally conserved in other B-family DNA polymerases, albeit its PolC motif carries amino acids substitutions at conserved $\mathrm{Y}$ and D (Fig. 1A). In contrast, the exonuclease domain is either absent or much more diverged from those present in the B-family replicative polymerases (Fig. 1A, Fig. S1).

To characterize Dpo2 biochemically, the encoding gene of S. islandicus was expressed in its native host and purified into an apparent homogeneity (Fig. S2). The purified Dpo2 was assayed for the basic properties and for the optima of the primer extension reaction (Fig. S3), using the substrate shown in Fig. 1B. These included determination of its optimal values in reaction $\mathrm{pH}$, temperature and salt content as well as the metal ion preference. As shown in Fig. S3A, the activity of $\mathrm{Dpo} 2$ increased along with the increase of $\mathrm{pH}$ from 6.0 to 8.0, before shallowing down at $\mathrm{pH} 8.8$. Longest synthesized DNA fragments appeared in the reactions of $\mathrm{pH} 8.0$ and 8.4, suggesting this $\mathrm{pH}$ range is optimal for the polymerase. As a result, subsequent optimization of the Dpo2 assay was conducted with buffers containing $50 \mathrm{mM}$ Tris-Cl pH 8.0. The effect of salt on the activity of Dpo2 was tested with both $\mathrm{KCl}$ and $\mathrm{NaCl}$. We found that the S. islandicus Dpo2 was most active at the low salt buffer, and in fact, $80 \mathrm{mM} \mathrm{KCl}$ or $20 \mathrm{mM} \mathrm{NaCl}$ could already inhibit the Dpo2 activity (Fig. S3B). Six different divalent metal ions $\left(\mathrm{Mg}^{2+}, \mathrm{Mn}^{2+}, \mathrm{Ca}^{2+}, \mathrm{Zn}^{2+}, \mathrm{Ni}^{2+}, \mathrm{Fe}^{2+}\right)$ were tested for their capability of supporting the polymerization activity, and this revealed that both magnesium and manganese ions supported the Dpo2 activity. Furthermore, Dpo2 showed a higher activity in the presence of the equal concentration of the manganese ion relative to the magnesium ion (Fig. S3D), as reported for many specialized DNA polymerases [32; 33; 34; 35; 36]. Nevertheless, $\mathrm{Mg}^{2+}$ was used in the following analysis, considering a much higher physiological concentration for this metal ion in different cells. In addition, the optimal reaction temperature and dNTP concentration determined for Dpo2 were $55-65{ }^{\circ} \mathrm{C}$ and $100-500 \mu \mathrm{M}$, respectively (Fig. S3). To this end, the optimized buffer system for Dpo2 was defined as $50 \mathrm{mM}$ Tris- $\mathrm{HCl} \mathrm{pH} 8.0,40 \mathrm{mM} \mathrm{KCl}, 0.1 \mathrm{mg} / \mathrm{ml}$ BSA, $10 \mathrm{mM} \mathrm{MgCl}_{2}, 100 \mu \mathrm{M}$ dNTPs, which was employed for all primer extension assays.

Using the optimized reaction system, we examined the nucleotide incorporation activity of Dpo2, in comparison with Dpo1, the replicase of this crenarchaeon [8]. The enzyme concentrations tested for Dpo2 and Dpo1 were $0.4-400 \mathrm{nM}$ and $0.4-50 \mathrm{nM}$, respectively, and this revealed that Dpo2 manifested DNA polymerization at a concentration as low as $3 \mathrm{nM}$, and the amount of primer consumed by Dpo2 in this assay was comparable to that converted by Dpo1 at the identical or a very similar enzyme concentration (Fig. 1B). These results indicated that Dpo2 exhibits a robust nucleotide incorporation activity. Noticeably, while the replicase readily extended the primer into full length products (with $13 \mathrm{nM}$ Dpo1), the Dpo2 polymerization yielded DNA fragments of different sizes in the reactions with the same or a higher enzyme concentration (Fig. 1B). These data suggested that the $S$. islandicus $\mathrm{Dpo} 2$ is a distributive polymerase, relative to the processive Dpo1 enzyme.

To test if the $S$. islandicus Dpo2 could perform proof-reading during DNA synthesis, the mismatched primer-templates (including T:C, T:G and T:T mismatches) were mixed individually with Dpo2 $(25,100$ or $400 \mathrm{nM})$ as well as Dpo1 $(5,25$, or $100 \mathrm{nM})$, the latter of which is known to possess the $3^{\prime}-5^{\prime}$ exonuclease activity. After incubation at $60^{\circ} \mathrm{C}$ for $5 \mathrm{~min}$, samples were analyzed by the denaturing PAGE. As shown in Fig. 1C, while $25 \mathrm{nM}$ Dpol effectively degraded all three primers from the 3'-terminus, generating a ladder of degraded oligonucleotides, 16-fold more Dpo2 
enzyme did not show any detectable 3 ' -5 ' exonuclease activity since full-length primers remained intact in the reaction with $400 \mathrm{nM}$ Dpo2.

Taken together, the $S$. islandicus Dpo2 represents a unique PolB exhibiting robust nucleotideincorporation, poor processivity and no detectable exonuclease activity.

\section{Dpo2 replicates undamaged DNA with high fidelity}

Next, we sought to decipher kinetic parameters of nucleotide incorporation by this unique B-family enzyme, using the steady-state kinetic assay described in the Materials and Methods. Dpo2 was evaluated for the fidelity of nucleotide incorporation opposite each of the four template bases. As summarized in Table 1, Dpo2 is clearly able to discriminate correct and incorrect incoming nucleotide, as it incorporated correct nucleotides opposite different template base with highest efficiency $\left(\mathrm{K}_{\mathrm{cat}} / \mathrm{K}_{\mathrm{m}}\right)$ and with lowest $\mathrm{K}_{\mathrm{m}}$ values. Overall, insertion of a wrong nucleotide (misincorporation) by Dpo2 occurred at a frequency ranging from $2.8 \times 10^{-5}$ (for inserting a $\mathrm{C}$ opposite a template base $\mathrm{C}$ ) to $5.37 \times 10^{-4}$ (for inserting a $\mathrm{G}$ opposite an A). Thus, the misincorporation frequency of this unique PolB on four different template base is from $10^{-4}$ to $10^{-}$ ${ }^{5}$, falling into the same range of the replication fidelity by the $S$. solfataricus replicase Dpo1 at 37 ${ }^{\circ} \mathrm{C}$ [37] and its exonuclease-minus mutant, Dpo1 exo- at $55^{\circ} \mathrm{C}$ [9]. Thus, Dpo2 is a high-fidelity DNA polymerase on undamaged DNA templates.

\section{Dpo2 is proficient in extension of mismatched primer termini}

To test if Dpo2 could extend mismatched base pair ends, we determined the ability of Dpo2 to elongate 4 matched and 12 mismatched primer-templates (Table S2), using the steady state kinetics assay. As summarized in Table 2, the frequencies of Dpo $2\left(f^{0}{ }_{\text {ext }}\right)$ in mismatch extension from A:A, $\mathrm{A}: \mathrm{G}$ and G:T mispairs were estimated to $4.5 \times 10^{-1}, 1.3 \times 10^{-1}$ and $2.6 \times 10^{-1}$ respectively, and $f_{\text {ext }}^{0}$ values for extension from most of the rest mispairs were found to be in the order of $10^{-2}$. These results indicated that Dpo2 can effectively extend mismatched DNA ends.

To better illustrate the properties of Dpo2 in the nucleotide polymerization, its $f_{\text {inc }}$ values (x-axis) for inserting a wrong nucleotide opposite a template (Table 1) were plotted against the

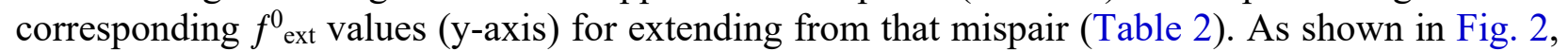
data points are scattered at the upper left part of the figure. These data indicated that Dpo 2 exhibits a much higher efficiency in the mismatch extension than in the mispair formation $\left(10^{-1}-10^{-3}\right.$ vs $10^{-}$ $\left.{ }^{4}-10^{-5}\right)$, and the enzyme preferably extends primer termini ended with $\mathrm{dG}, \mathrm{dA}$ and wobble base-pair (T:G and G:T). These results are in strict contrast to an almost equal efficiency in the mispair formation and in the mismatch extension for Dpo4 and other non-extender DNA polymerases (Johnson et al., 2000; Pavlov et al., 2006), whose data points scatter along the dash line in Fig. S3. Thus, we reasoned that Dpo2 could function as a mismatch extender in Sulfolobus.

\section{Dpo2 functions as a DNA lesion extender}

The exceptional capability of mispair extension by Dpo2 prompted us to test its activity in translesion DNA synthesis. Three DNA lesions were chosen for the experiment, including AP site, cis-syn cyclobutane pyrimidine dimer (CPD) and 8-oxo-7,8-dihydro-2'-deoxyguanosine (8-oxodG), all of which are common forms of DNA damage encountered by a thermophilic acidophile. The DNA template designed for the AP site bypass experiments was a $37 \mathrm{nt}$ oligonucleotide containing a synthetic abasic site (tetrahydrofuran analogue) at 17th position (Table S2). Two primers were then designed, one extends to the -1 position of the AP site of the template (for "AP insertion" assay), while the other, to the position opposite the abasic site (for "AP extension" assay). Annealing of the DNA template with each of the primers yielded two series of primer-template 
substrates, for the experiments of "AP insertion" and "AP extension", respectively. Seven reactions were setup for each assay, in which only the Dpo2 content varied within the indicated range. After incubation for $10 \mathrm{~min}$, primer extension products were analyzed by the denaturing polyacrylamide gel electrophoresis (PAGE). As shown in Fig. 3B, in the AP insertion assay, the signal of primer extension products was hardly detectable at the position across the lesion and beyond even in the presence of $800 \mathrm{nM}$ Dpo2. This enzyme concentration is 100 -fold higher than the efficient primer extension on an undamaged DNA template by the polymerase (Fig. 3A). Intriguingly, when the abasic site was covered by the terminal nucleotide of a primer (AP extension), +1 extension product was already detected with $25 \mathrm{nM} \mathrm{Dpo2}$, the lowest enzyme concentration tested here. Furthermore, the size of extension products increased along with the elevation of the Dpo 2 concentration, and all primers were converted into longer products at $200 \mathrm{nM}$ enzyme (Fig. 3A). These data indicated that Dpo2 works as an extender polymerase in the TLS bypass of abasic sites.

When a DNA template carrying a cis-syn cyclobutane pyrimidine dimer (CPD) was employed, we found again that Dpo2 failed to insert any nucleotide opposite the lesion, but it was capable of extending mispaired primer ends, albeit at an efficiency lower than the extension of the APcontained mispaired primer ends (Fig. 3C). In the case of the 8-oxodG bypass reaction, Dpo2 incorporated a nucleotide across the 8 -oxodG lesion for $53.8 \%$ of the template even at the highest concentration $(800 \mathrm{nM})$ of the enzyme tested in this study, indicative of a very weak activity in the TLS insertion. In contrast, the Dpo2 extension is robust since a comparable amount of substrate has rapidly been extended at an 8-fold lower concentration (100 nM) (Fig. 3D).

\section{S. solfataricus Dpo2 is also a robust DNA polymerase lacking proofreading}

We noticed that our results with the $S$. islandicus Dpo2 are in contrast to those obtained with the $S$. solfataricus $\mathrm{Dpo} 2$ (SsoDpo2) that expressed in an E. coli host in a previous work. In the latter only weak activities were observed in polymerization and in proofreading for the heterlogously expressed form of SsoDpo2 [37]. Since Dpo2 proteins of S. solfataricus and S. islandicus share $91 \% / 96 \%$ sequence identity/similarity, it is very unlikely the two proteins would exhibit any major differences in enzymatic properties. SsoDpo2 was then expressed in S. islandicus, and the enzyme was purified and characterized along with the S. islandicus Dpo2 (Fig. S5). We found that, as for the S. islandicus Dpo2, the recombinant SsoDpo2 obtained from the Sulfolobus host showed two striking features: (a) it does not possess any detectable $5^{\prime}-3^{\prime}$ exonuclease activity, which is consistent with the lack of the Exo motifs, and (b) the PolB enzyme is highly efficient in nucleotide incorporation, exhibiting a strong propensity in mismatch extension and AP extension during DNA synthesis (Fig. 4).

Taken together, the above results indicated that PolB2s are very inefficient in the misincoporation and TLS insertion, but show robust activity in mismatch and lesion extension. Thus they probably function as mismatch and lesion extenders in the archaeal translesion DNA synthesis.

\section{DISCUSSION}

Members of PolB2 enzymes are widespread in Archaea. This group of DNA polymerases are unique since they carry deletions or radical variation in exo motifs and variations in key amino acid residues of the PolC motif that are very conserved in all other groups of PolB enzymes [21;38]. For this reason, PolB2 was regarded as a group of inactivated DNA polymerases. Here, we report that both $S$. islandicus and S. solfataricus Dpo2 enzymes are very active in nucleotide incorporation since their activities are comparable to that of Dpo1, the replicase that co-exists in these archaeal organisms. We further show that the archaeal PolB2s lack any detectable 5'-3' nuclease activity 
and they are proficient in mismatch and lesion extension. Our results suggest the archaeal PolB2 enzymes represent a novel type of PolB that play important roles in DNA damage repair.

Our identification of the robust DNA polymerase activity for the Sulfolobus Dpo2 has yielded important insights into the mechanisms of DNA synthesis. B-family DNA polymerases share conserved motifs three of which (Exo I, II, III) are located in the proof-reading domain while the remaining (e.g., PolA, B, C) are in the polymerase domain (Fig. 1A). The PolB2 group of DNA pols exhibit numerous variations in these motifs. The Sulfolobus Dpo2 proteins investigated in this work represent the smallest PolB2 known to date (Fig. S6). These enzymes lack most of the conserved amino acids in the proofreading domain and exhibit large variations in the PolC motif. The latter is in contrast to the members of other PolB groups since their PolCs have the YxDTD invariant motif, which is replaced with HxxxD in PolB2. It has been reported that PolC motif of Bfamily DNA pols plays a key role in primer/template recognition and participates in the coordination of the catalytic $\mathrm{Mg}^{2+}$ that is essential for the polymerization reaction [39; 40]. Nevertheless, previous works have already shown that the two Asp residues in PolC are not equally important for catalysis of DNA polymerization. Structural interrogation of a few B-family DNA polymerases has revealed that the second aspartate is responsible for the metal ion coordination whereas the first Asp is orientated away from the activity center [40;41;42;43; 44]. Since mutagenesis of the first Asp greatly reduces the activity of the human Pol $\alpha$ and two viral replicases [45; 46; 47], this acidic amino acid, although not directly involved in catalysis, still plays an important role in the polymerase activity. However, our work shows that Sulfolobus Dpo2 enzymes, although lacking the first Asp of PolC, are as active as the Dpol replicase in nucleotide incorporation. This suggests the function of the first Asp in the PolC motif can be functionally replaced by His, an invariant amino acid in the PolC motif of the PolB2 enzymes (Fig. 1A). In addition, mutation of amino acid residues adjacent to the catalytic Asp in the PolC motif of the $E$. coli Pol I or Thermus aquaticus (Taq) polymerase impairs their mismatch extension ability [48; 49]. To this end, we reason that the sequence variation at the PolC motif in the PolB2 enzymes could reflect their adaptation to their specialized function in DNA repair, which apparently requires a robust nucleotide incorporation activity and the tolerance of DNA damage whereas their replication processivity and proofreading are disfavored.

Noticeably, the properties of the recombinant SsoDpo2 we have obtained from $S$. islandicus, a homologous host are very different from the same enzyme yielded from heterologous expression in E. coli [37]. While the E. coli recombinant SsoDpo2 (500 nM) exhibits optimal activity at $50{ }^{\circ} \mathrm{C}$, and the activity is greatly reduced at $60{ }^{\circ} \mathrm{C}$ and completely inactivated at $70{ }^{\circ} \mathrm{C}$ [37], the optimal temperature for the Sulfolobus-expressed SsoDpo2 $(17.5 \mathrm{nM})$ is $50-65{ }^{\circ} \mathrm{C}$ and the enzyme is still active in $80-90{ }^{\circ} \mathrm{C}$ (Fig. S5). We reason that the observed differences can be attributed to differences in posttranslational modifications (PTMs) present in proteins produced in the thermophilic host versus those synthesized in the mesophilic host [50]. Indeed, in a comparative study of a recombinant $S$. islandicus esterase produced in $S$. islandicus versus that produced in $E$. coli, the homologously expressed protein is much more active than the heterologously expressed version of the same enzyme [51]. In addition, Dpo2 contains 7 cysteine residues and their potential of generating intra- and/or intermolecular disulfide bonds may differ strongly in a different genetic background, which also contribute to the differences observed between the two forms of SsoDpo2 recombinant protein.

Our characterization of the archaeal Dpo2 enzymes has revealed that PolB2 enzymes exhibit several distinctive biochemical features, including: (a) the lack of a proof-reading activity, (b) its promiscuous extension of mispaired primer ends can fix mismatches and (c) its capacity in lesion extension may generate mutations. The unique features are consistent with their possible functions in DNA damage repair in these crenarchaea as recently revealed from our genetic analyses in $S$. islandicus using the gene disruptant strains for $d p o 2$, $d p o 3$, and $d p o 4$, respectively. Comparison of 
their phenotypes with that of the wild-type reference has revealed that Dpo2 is solely responsible for the targeted mutagenesis in this crenarchaeon [20]. These unique features of Dpo2 may have provided the molecular mechanisms for the generation of the Dpo2-dependent targeted mutagenesis observed in our genetic study [20]. In this regard, Dpo2 is analogous to the eukaryotic Pol $\zeta$ since its deficiency also reduces the targeted mutations in yeast $[52 ; 53]$ and this B-family DNA polymerase also known for the lack of proofreading activity and the exceptional ability in mismatch extension [54]. Considering Pol $\zeta$ working in concert with Y-family DNA polymerases (Pol 1 or Pol $\eta$ ) in a two-polymerase mechanism for AP lesion bypass in Eukarya [29; 55], Thus, the identification of PolB2 enzymes as a mismatch and lesion extender raises an intriguing question about whether it also acts in concert with other DNA polymerase in Archaea to facilitates lesion bypass in the domain of Archaea.

\section{AUTHOR CONTRIBUTIONS}

QS and XF designed the work. XF, BZ, ZG, RX, XL, MF, SI, YS, YI and QS contributed to the acquisition and analysis of the data. XF, BZ, QS, SI, YI and YS interpreted the data. QS and XF wrote the manuscript, and SI, YI and YS revised it.

\section{CONFLICT OF INTEREST}

The authors declare that they have no conflict of interest.

\section{FUNDING}

This work was supported by grants from the National Key R \& D Program of China (2020YFA0906800 to QS), the National Natural Science Foundation of China (Grant No. 32001022 to XF; 31670061 and 31970546 to YS), Shandong University and Japan Society for the Promotion of Science (JSPS) KAKENHI Grant (No. JP80399740 to SI and JP19K22289 to YI). Funding for open access charge: National Key R \& D Program of China.

\section{ACKNOWLEDGEMENT}

We thank Dr. Likui Zhang at Yangzhou University for advices in kinetic studies and Dr. Li Huang at Institute of Microbiology, Chinese Academy of Sciences for stimulating discussions.

\section{DATA AVAILABILITY}

All data required to evaluate the conclusions of this study can be found in either the main text or the Supplementary data.

\section{REFERENCES}

1. Yang W, Gao Y. Translesion and Repair DNA Polymerases: Diverse Structure and Mechanism. Annu Rev Biochem. 2018;87:239-61.

2. Makarova KS, Krupovic M, Koonin EV. Evolution of replicative DNA polymerases in archaea and their contributions to the eukaryotic replication machinery. Front Microbiol. 2014;5:354.

3. Lujan SA, Williams JS, Kunkel TA. DNA Polymerases Divide the Labor of Genome Replication. Trends Cell Biol. 2016;26(9):640-54. 
4. Yao NY, O'Donnell ME. Evolution of replication machines. Crit Rev Biochem Mol Biol. 2016;51(3):135-49.

5. Goodman MF, Woodgate R. Translesion DNA polymerases. Cold Spring Harb Perspect Biol. 2013;5(10):a010363.

6. She Q, Singh RK, Confalonieri F, Zivanovic Y, Allard G, Awayez MJ, et al. The complete genome of the crenarchaeon Sulfolobus solfataricus P2. Proc Natl Acad Sci U S A. 2001;98(14):7835-40.

7. Chen L, Brugger K, Skovgaard M, Redder P, She Q, Torarinsson E, et al. The genome of Sulfolobus acidocaldarius, a model organism of the Crenarchaeota. J Bacteriol. 2005;187(14):4992-9.

8. Guo L, Brugger K, Liu C, Shah SA, Zheng H, Zhu Y, et al. Genome analyses of Icelandic strains of Sulfolobus islandicus, model organisms for genetic and virus-host interaction studies. J Bacteriol. 2011;193(7):1672-80.

9. Yan J, Beattie TR, Rojas AL, Schermerhorn K, Gristwood T, Trinidad JC, et al. Identification and characterization of a heterotrimeric archaeal DNA polymerase holoenzyme. Nat Commun. 2017;8:15075.

10. Zhang L, Lou H, Guo L, Zhan Z, Duan Z, Guo X, et al. Accurate DNA synthesis by Sulfolobus solfataricus DNA polymerase B1 at high temperature. Extremophiles. 2010;14(1):10717.

11. Bauer RJ, Begley MT, Trakselis MA. Kinetics and fidelity of polymerization by DNA polymerase III from Sulfolobus solfataricus. Biochemistry. 2012;51(9):1996-2007.

12. Boudsocq F, Iwai S, Hanaoka F, Woodgate R. Sulfolobus solfataricus P2 DNA polymerase IV (Dpo4): an archaeal DinB-like DNA polymerase with lesion-bypass properties akin to eukaryotic poleta. Nucleic Acids Res. 2001;29(22):4607-16.

13. Ling H, Boudsocq F, Woodgate R, Yang W. Snapshots of replication through an abasic lesion; structural basis for base substitutions and frameshifts. Mol Cell. 2004;13(5):751-62.

14. Rechkoblit O, Malinina L, Cheng Y, Kuryavyi V, Broyde S, Geacintov NE, et al. Stepwise translocation of Dpo4 polymerase during error-free bypass of an oxoG lesion. PLoS Biol. 2006;4(1):e11.

15. Fiala KA, Suo Z. Sloppy bypass of an abasic lesion catalyzed by a Y-family DNA polymerase. J Biol Chem. 2007;282(11):8199-206.

16. Gotz D, Paytubi S, Munro S, Lundgren M, Bernander R, White MF. Responses of hyperthermophilic crenarchaea to UV irradiation. Genome Biol. 2007;8(10):R220.

17. Frols S, Gordon PM, Panlilio MA, Duggin IG, Bell SD, Sensen CW, et al. Response of the hyperthermophilic archaeon Sulfolobus solfataricus to UV damage. J Bacteriol. 2007;189(23):8708-18.

18. Sun M, Feng X, Liu Z, Han W, Liang YX, She Q. An Orc 1/Cdc6 ortholog functions as a key regulator in the DNA damage response in Archaea. Nucleic Acids Res. 2018;46(13):6697711.

19. Feng X, Sun M, Han W, Liang YX, She Q. A transcriptional factor B paralog functions as an activator to DNA damage-responsive expression in archaea. Nucleic Acids Res. 2018;46(14):7085-96. 
20. Schult F, Le TN, Albersmeier A, Rauch B, Blumenkamp P, van der Does C, et al. Effect of UV irradiation on Sulfolobus acidocaldarius and involvement of the general transcription factor TFB3 in the early UV response. Nucleic Acids Res. 2018;46(14):7179-92.

21. Feng X, Liu X, Xu R, Zhao R, Feng W, Liao J, et al. A Unique B-Family DNA Polymerase Facilitating Error-Prone DNA Damage Tolerance in Crenarchaeota. Front Microbiol. 2020;11(1585):1585 doi: 10.3389/fmicb.2020.01585.

\section{Rogozin IB, Makarova KS, Pavlov YI, Koonin EV. A highly conserved family of} inactivated archaeal B family DNA polymerases. Biol Direct. 2008;3:32.

23. Deng L, Zhu H, Chen Z, Liang YX, She Q. Unmarked gene deletion and host-vector system for the hyperthermophilic crenarchaeon Sulfolobus islandicus. Extremophiles. 2009;13(4):735-46.

\section{Contursi P, Jensen S, Aucelli T, Rossi M, Bartolucci S, She Q. Characterization of the} Sulfolobus host-SSV2 virus interaction. Extremophiles. 2006;10(6):615-27.

25. Peng N, Deng L, Mei Y, Jiang D, Hu Y, Awayez M, et al. A synthetic arabinose-inducible promoter confers high levels of recombinant protein expression in hyperthermophilic archaeon Sulfolobus islandicus. Appl Environ Microbiol. 2012;78(16):5630-7.

26. Feng X, Liu X, Xu R, Zhao R, Feng W, Liao J, et al. A Unique B-Family DNA Polymerase Facilitating Error-Prone DNA Damage Tolerance in Crenarchaeota. Frontiers in Microbiology. 2020;11(1585).

27. Feng X, She Q. Recombinant protein expression in Sulfolobus islandicus. Methods in Enzymol. 2021;659.

28. Bradford MM. A rapid and sensitive method for the quantitation of microgram quantities of protein utilizing the principle of protein-dye binding. Anal Biochem. 1976;72:248-54.

29. O'Flaherty DK, Guengerich FP. Steady-state kinetic analysis of DNA polymerase singlenucleotide incorporation products. Curr Protoc Nucleic Acid Chem. 2014;59:7 21 1-13.

30. Johnson RE, Washington MT, Haracska L, Prakash S, Prakash L. Eukaryotic polymerases iota and zeta act sequentially to bypass DNA lesions. Nature. 2000;406(6799):1015-9.

31. Mendelman LV, Petruska J, Goodman MF. Base mispair extension kinetics. Comparison of DNA polymerase alpha and reverse transcriptase. J Biol Chem. 1990;265(4):2338-46.

32. Vaisman A, Tissier A, Frank EG, Goodman MF, Woodgate R. Human DNA polymerase iota promiscuous mismatch extension. J Biol Chem. 2001;276(33):30615-22.

33. Vashishtha AK, Wang J, Konigsberg WH. Different Divalent Cations Alter the Kinetics and Fidelity of DNA Polymerases. J Biol Chem. 2016;291(40):20869-75.

34. Garcia-Gomez S, Reyes A, Martinez-Jimenez MI, Chocron ES, Mouron S, Terrados G, et al. PrimPol, an archaic primase/polymerase operating in human cells. Mol Cell. 2013;52(4):54153.

35. Frank EG, Woodgate R. Increased catalytic activity and altered fidelity of human DNA polymerase iota in the presence of manganese. J Biol Chem. 2007;282(34):24689-96.

36. Blanca G, Shevelev I, Ramadan K, Villani G, Spadari S, Hubscher U, et al. Human DNA polymerase lambda diverged in evolution from DNA polymerase beta toward specific $\mathrm{Mn}(++)$ dependence: a kinetic and thermodynamic study. Biochemistry. 2003;42(24):7467-76.

37. Martin MJ, Garcia-Ortiz MV, Esteban V, Blanco L. Ribonucleotides and manganese ions improve non-homologous end joining by human Polmu. Nucleic Acids Res. 2013;41(4):2428-36. 
38. Choi JY, Eoff RL, Pence MG, Wang J, Martin MV, Kim EJ, et al. Roles of the four DNA polymerases of the crenarchaeon Sulfolobus solfataricus and accessory proteins in DNA replication. J Biol Chem. 2011;286(36):31180-93.

39. Kazlauskas D, Krupovic M, Guglielmini J, Forterre P, Venclovas C. Diversity and evolution of B-family DNA polymerases. Nucleic Acids Res. 2020;48(18):10142-56.

40. Bernad A, Blanco L, Salas M. Site-directed mutagenesis of the YCDTDS amino acid motif of the phi 29 DNA polymerase. Gene. 1990;94(1):45-51.

41. Franklin MC, Wang J, Steitz TA. Structure of the replicating complex of a pol alpha family DNA polymerase. Cell. 2001;105(5):657-67.

42. Swan MK, Johnson RE, Prakash L, Prakash S, Aggarwal AK. Structural basis of highfidelity DNA synthesis by yeast DNA polymerase delta. Nat Struct Mol Biol. 2009;16(9):979-86.

43. Zahn KE, Tchesnokov EP, Gotte M, Doublie S. Phosphonoformic acid inhibits viral replication by trapping the closed form of the DNA polymerase. J Biol Chem. 2011;286(28):25246-55.

44. Zhang HX, Li Y, Wang X, Xiao ZT, Wang YH. Insight into the structural requirements of benzothiadiazine scaffold-based derivatives as hepatitis $\mathrm{C}$ virus NS5B polymerase inhibitors using 3D-QSAR, molecular docking and molecular dynamics. Curr Med Chem. 2011;18(26):4019-28.

45. Brautigam CA, Steitz TA. Structural and functional insights provided by crystal structures of DNA polymerases and their substrate complexes. Curr Opin Struct Biol. 1998;8(1):54-63.

46. Saturno J, Lazaro JM, Blanco L, Salas M. Role of the first aspartate residue of the "YxDTDS" motif of phi29 DNA polymerase as a metal ligand during both TP-primed and DNAprimed DNA synthesis. J Mol Biol. 1998;283(3):633-42.

47. Copeland WC, Wang TS. Mutational analysis of the human DNA polymerase alpha. The most conserved region in alpha-like DNA polymerases is involved in metal-specific catalysis. J Biol Chem. 1993;268(15):11028-40.

48. Zakharova E, Wang J, Konigsberg W. The activity of selected RB69 DNA polymerase mutants can be restored by manganese ions: the existence of alternative metal ion ligands used during the polymerization cycle. Biochemistry. 2004;43(21):6587-95.

49. Summerer D, Rudinger NZ, Detmer I, Marx A. Enhanced fidelity in mismatch extension by DNA polymerase through directed combinatorial enzyme design. Angew Chem Int Ed Engl. 2005;44(30):4712-5.

50. Strerath M, Gloeckner C, Liu D, Schnur A, Marx A. Directed DNA polymerase evolution: effects of mutations in motif $\mathrm{C}$ on the mismatch-extension selectivity of thermus aquaticus DNA polymerase. Chembiochem. 2007;8(4):395-401.

51. Gong P, Lei P, Wang S, Zeng A, Lou H. Post-Translational Modifications Aid Archaeal Survival. Biomolecules. 2020;10(4).

52. Mei Y, Peng N, Zhao S, Hu Y, Wang H, Liang Y, et al. Exceptional thermal stability and organic solvent tolerance of an esterase expressed from a thermophilic host. Appl Microbiol Biotechnol. 2012;93(5):1965-74.

53. Prakash L. Effect of Genes Controlling Radiation Sensitivity on Chemically Induced Mutations in SACCHAROMYCES CEREVISIAE. Genetics. 1976;83(2):285-301.

54. Lemontt JF. Induction of forward mutations in mutationally defective yeast. Mol Gen Genet. 1972;119(1):27-42. 
A novel specialized B-family DNA polymerase

518 55. Prakash S, Johnson RE, Prakash L. Eukaryotic translesion synthesis DNA polymerases:

519 specificity of structure and function. Annu Rev Biochem. 2005;74:317-53.

520 56. Yuan F, Zhang Y, Rajpal DK, Wu X, Guo D, Wang M, et al. Specificity of DNA lesion 521 bypass by the yeast DNA polymerase eta. J Biol Chem. 2000;275(11):8233-9. 
A novel specialized B-family DNA polymerase

Figure 1. Dpo2 is robust in DNA polymerization but deficient in proofreading activity

526

527

528

529

530

531

532

533

534

535

536

537

538

539

540

541

542

543

(A) Sequence alignment of a few selected B-family DNA Polymerases. Only the selected regions of the exonuclease domain and polymerase domain are shown and the full sequence alignment was shown in Fig S1. SsoDpo1, S. solfataricus Dpo1. SisDpo1, S. islandicus Dpo1. SsoDpo3, S. solfataricus Dpo3. PfuPolB, Pyrococcus furiosus PolB. Tgo_PolB, Thermococcus gorgonarius PolB. ScePoldelta, The catalytic subunit of Saccharomyces cerevisiae Pol $\delta$. AsgardPolB2, Candidatus Thorarchaeota archaeon PolB2. HvoPolB2, Haloferax volcanii PolB2. ApePolB2, Aeropyrum pernix PolB2. Ec_Pol_II, E. coli Pol II. Structures of SsoDpo1 (1S5J) was used as the templates for the structure-based sequence alignment. The secondary structural elements shown above the sequences were retrieved from the structure file of SsoDpol (1S5J) (B) Primer extension activities of Dpo2 and Dpo1. Reactions were set up with $50 \mathrm{nM}$ primer-template, $100 \mu \mathrm{M}$ dNTPs and a concentration gradient of Dpo2 or Dpo1 (indicated above their gel images in each panel). After incubation at $60^{\circ} \mathrm{C}$ for $10 \mathrm{~min}$, extension products were analyzed by denaturing PAGE. Note: Dpo1 yielded an extension product of $37 \mathrm{nt}$, which is one nucleotide longer than the template (36 $\mathrm{nt}$ ), indicative of a strong TdT (terminal transferase) activity of the enzyme. In contrast, Dpo2 only showed a low TdT activity. (C) Proofreading by Dpo2 and Dpo1. Exonuclease assay was set up with $50 \mathrm{nM}$ mismatched primer-template and a gradient concentration of Dpo2 or Dpo1 in the absence of dNTPs. After incubation at $60{ }^{\circ} \mathrm{C}$ for $5 \mathrm{~min}$, the products were analyzed by denaturing PAGE. $\mathrm{N}$ denotes each of the four possible primer terminal nucleotides as indicated.

Figure 2. Dpo2 is proficient in extension of mismatched primer termini.

Values of $f_{\text {ext }}^{0}$ (the ratio of the apparent $\mathrm{K}_{\text {cat }} / \mathrm{K}_{\mathrm{m}}$ of extension from the mismatched base pair to the apparent $\mathrm{K}_{\mathrm{cat}} / \mathrm{K}_{\mathrm{m}}$ of extension from matched base pair) presented in Supplementary Table S4 were plotted against the values of misincorporation frequency $\left(f_{\text {inc }}\right)$ shown in Supplementary Table S3. The dash line corresponds to $f_{\text {ext }}^{0}=f_{\text {inc. }}$.

\section{Figure 3. Dpo2 is a lesion extender.}

DNA substrates employed for primer extension assay were illustrated above the corresponding gel images. Templates in the substrates are of 4 different types: (A) Undamaged template, which is either lesion-free (undamaged); (B) template carrying an AP lesion, which is highlighted in red in the backbone; (C) template carrying TT-CPD, which is shown as two parallel bars adjoined with two red lines, and (D) template containing 8-oxodG (shown as "G" base carrying a red hat). Numbers in parentheses indicate lengths of primers and templates in each substrate. Primer extension was conducted with reaction mixes containing Dpo 2 of varied concentrations (indicated below gel images) and analyzed by denaturing PAGE. Numbers in the size marker denote the lengths of nucleotides.

\section{Figure 4. SsoDpo2 has a similar activity as SisDpo2}

(A) Exonuclease assay. The assay was set up with $50 \mathrm{nM}$ substrate and enzyme concentrations indicated above each lane. Reactions were conducted at $60{ }^{\circ} \mathrm{C}$ for $5 \mathrm{~min}$. (B) Extension of the undamaged substrate (A:T) and mismatched substrate (T:T). Substrates used for the assays are the same as shown in Fig. 1. Each reaction contains $100 \mathrm{nM}$ DNA polymerase and $50 \mathrm{nM}$ substrate. N: no enzyme control. (C) AP insertion and extension. Assays were set up with the substrates shown in Fig. 3B. Primer extension reactions were conducted with $50 \mathrm{nM}$ substrates. 
TABLES

Table 1. Steady-state kinetic parameters of deoxynucleotide incorporation by Dpo2 on undamaged DNA

\begin{tabular}{|c|c|c|c|c|c|}
\hline $\begin{array}{c}\text { Template } \\
\text { base }\end{array}$ & $\begin{array}{l}\text { Incoming } \\
\text { dNTP }\end{array}$ & $\begin{array}{l}\mathrm{K}_{\mathrm{m}} \\
(\mu \mathrm{M})\end{array}$ & $\begin{array}{l}\mathrm{K}_{\text {cat }} \\
\left(\mathrm{min}^{-1}\right)\end{array}$ & $\begin{array}{c}\mathrm{K}_{\mathrm{cat}} / \mathrm{K}_{\mathrm{m}} \\
\left(\mu \mathrm{M}^{-1} \mathrm{~min}^{-1}\right)\end{array}$ & $f_{\text {inc }}$ \\
\hline \multirow[t]{4}{*}{ A } & $\mathrm{A}$ & $1205 \pm 201$ & $0.0112 \pm 0.0022$ & $9.3 \times 10^{-6}$ & $1.91 \times 10^{-4}$ \\
\hline & $\mathrm{T}$ & $39.9 \pm 14.9$ & $1.94 \pm 0.41$ & $4.9 \times 10^{-2}$ & 1 \\
\hline & G & $902 \pm 188$ & $0.0235 \pm 0.00076$ & $2.6 \times 10^{-5}$ & $5.37 \times 10^{-4}$ \\
\hline & $\mathrm{C}$ & $488 \pm 56.2$ & $0.00587 \pm 0.00015$ & $1.2 \times 10^{-5}$ & $2.48 \times 10^{-4}$ \\
\hline \multirow[t]{4}{*}{$\mathrm{T}$} & A & $118 \pm 10.6$ & $11.7 \pm 5.91$ & $9.9 \times 10^{-2}$ & 1 \\
\hline & $\mathrm{T}$ & $1616 \pm 91$ & $0.0234 \pm 0.0021$ & $1.5 \times 10^{-5}$ & $1.46 \times 10^{-4}$ \\
\hline & $\mathrm{G}$ & $1454 \pm 131$ & $0.0299 \pm 0.0040$ & $2.1 \times 10^{-5}$ & $2.08 \times 10^{-4}$ \\
\hline & $\mathrm{C}$ & $413 \pm 83.6$ & $0.00156 \pm 0.00028$ & $3.8 \times 10^{-6}$ & $3.81 \times 10^{-5}$ \\
\hline \multirow[t]{4}{*}{ G } & A & $982 \pm 75.9$ & $0.0118 \pm 0.0020$ & $1.2 \times 10^{-5}$ & $1.17 \times 10^{-4}$ \\
\hline & $\mathrm{T}$ & $1773 \pm 107$ & $0.0279 \pm 0.0077$ & $1.6 \times 10^{-5}$ & $1.53 \times 10^{-4}$ \\
\hline & $\mathrm{G}$ & $2474 \pm 628$ & $0.0257 \pm 0.0053$ & $1.0 \times 10^{-5}$ & $1.01 \times 10^{-4}$ \\
\hline & $\mathrm{C}$ & $40.6 \pm 5.78$ & $4.17 \pm 0.92$ & $1.0 \times 10^{-1}$ & 1 \\
\hline \multirow[t]{4}{*}{$\mathrm{C}$} & A & $1230 \pm 168$ & $0.0241 \pm 0.0047$ & $1.9 \times 10^{-5}$ & $3.17 \times 10^{-4}$ \\
\hline & $\mathrm{T}$ & $1428 \pm 130$ & $0.0084 \pm 0.0015$ & $5.9 \times 10^{-6}$ & $1.00 \times 10^{-4}$ \\
\hline & G & $62.1 \pm 8.54$ & $3.63 \pm 0.29$ & $5.8 \times 10^{-2}$ & 1 \\
\hline & $\mathrm{C}$ & $684 \pm 231$ & $0.00112 \pm 0.00032$ & $1.6 \times 10^{-6}$ & $2.80 \times 10^{-5}$ \\
\hline
\end{tabular}

$\mathrm{K}_{\mathrm{m}}$ and $\mathrm{K}_{\mathrm{cat}}$ values were determined by quantification of gel bands corresponding to substrates and products using ImageQuantTL, and the data were fitted into the Michaelis-Menten equation using Graphpad Prism. The nucleotide misincoporation ratio $\left(f_{\text {inc }}\right)$ was expressed as $\left(\mathrm{K}_{\text {cat }} / \mathrm{K}_{\mathrm{m}}\right)$ incorrect $/\left(\mathrm{K}_{\text {cat }} / \mathrm{K}_{\mathrm{m}}\right)$ correct. SD values means standard variations from three independent experiments. 
A novel specialized B-family DNA polymerase

574 Table 2. Steady-state kinetics parameters for mispair extension by Dpo2

\begin{tabular}{|c|c|c|c|c|c|}
\hline $\begin{array}{c}\text { Template } \\
\text { base }\end{array}$ & $\begin{array}{l}\text { Primer } \\
\text { base }\end{array}$ & $\begin{array}{l}\mathrm{K}_{\mathrm{m}} \\
(\mu \mathrm{M})\end{array}$ & $\begin{array}{c}\mathrm{K}_{\mathrm{cat}} \\
\left(\mathrm{min}^{-1}\right)\end{array}$ & $\begin{array}{c}\mathrm{K}_{\mathrm{cat}} / \mathrm{K}_{\mathrm{m}} \\
\left(\mu \mathrm{M}^{-1} \mathrm{~min}^{-1}\right)\end{array}$ & $f^{0}$ ext \\
\hline \multirow[t]{4}{*}{ A } & $\mathrm{A}$ & $55.0 \pm 5.0$ & $1.76 \pm 0.067$ & $3.2 \times 10^{-2}$ & $4.5 \times 10^{-1}$ \\
\hline & $\mathrm{T}$ & $55.2 \pm 14.5$ & $3.96 \pm 0.34$ & $7.2 \times 10^{-2}$ & 1 \\
\hline & $\mathrm{G}$ & $323 \pm 84.7$ & $3.09 \pm 0.21$ & $9.6 \times 10^{-3}$ & $1.3 \times 10^{-1}$ \\
\hline & $\mathrm{C}$ & $1129 \pm 222$ & $1.03 \pm 0.095$ & $9.1 \times 10^{-4}$ & $1.3 \times 10^{-2}$ \\
\hline \multirow[t]{4}{*}{$\mathrm{T}$} & A & $19.1 \pm 2.66$ & $35.9 \pm 3$ & 1.9 & 1 \\
\hline & $\mathrm{T}$ & $325 \pm 59.6$ & $1.43 \pm 0.34$ & $4.4 \times 10^{-3}$ & $2.3 \times 10^{-3}$ \\
\hline & G & $187 \pm 22$ & $21.5 \pm 8.91$ & $1.1 \times 10^{-1}$ & $6.1 \times 10^{-2}$ \\
\hline & $\mathrm{C}$ & $886 \pm 76.1$ & $19.7 \pm 5.89$ & $2.2 \times 10^{-2}$ & $1.2 \times 10^{-2}$ \\
\hline \multirow[t]{4}{*}{ G } & A & $514 \pm 57.2$ & $0.271 \pm 0.045$ & $5.3 \times 10^{-4}$ & $3.2 \times 10^{-2}$ \\
\hline & $\mathrm{T}$ & $476 \pm 112$ & $2.01 \pm 0.44$ & $4.2 \times 10^{-3}$ & $2.6 \times 10^{-1}$ \\
\hline & $\mathrm{G}$ & $517 \pm 123$ & $0.125 \pm 0.027$ & $2.4 \times 10^{-4}$ & $1.5 \times 10^{-2}$ \\
\hline & $\mathrm{C}$ & $86.1 \pm 11$ & $1.41 \pm 0.13$ & $1.6 \times 10^{-2}$ & 1 \\
\hline \multirow[t]{4}{*}{$\mathrm{C}$} & $\mathrm{A}$ & $405 \pm 33.6$ & $1.11 \pm 0.042$ & $2.8 \times 10^{-3}$ & $1.7 \times 10^{-2}$ \\
\hline & $\mathrm{T}$ & $479 \pm 80$ & $0.662 \pm 0.045$ & $1.4 \times 10^{-3}$ & $8.7 \times 10^{-3}$ \\
\hline & $\mathrm{G}$ & $21.6 \pm 6.3$ & $3.42 \pm 0.35$ & $1.6 \times 10^{-1}$ & 1 \\
\hline & $\mathrm{C}$ & $233 \pm 54.2$ & $0.461 \pm 0.05$ & $2.0 \times 10^{-3}$ & $1.2 \times 10^{-2}$ \\
\hline
\end{tabular}

575 Extension efficiency was examined with dGTP, the next correct nucleotide. 
A novel specialized B-family DNA polymerase

A

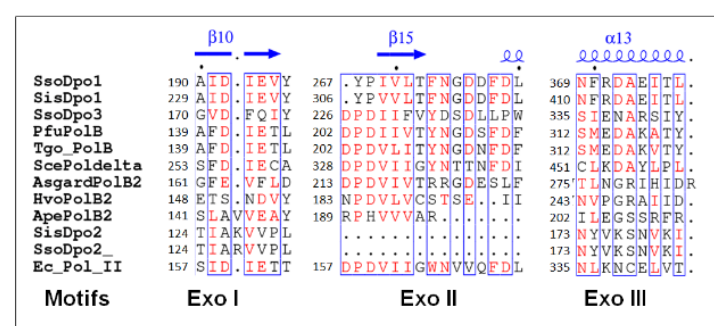

B

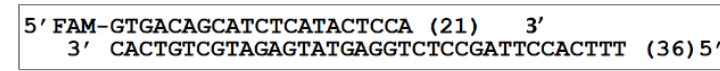

Dpo2 Dpo1

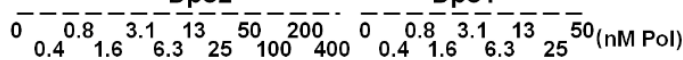

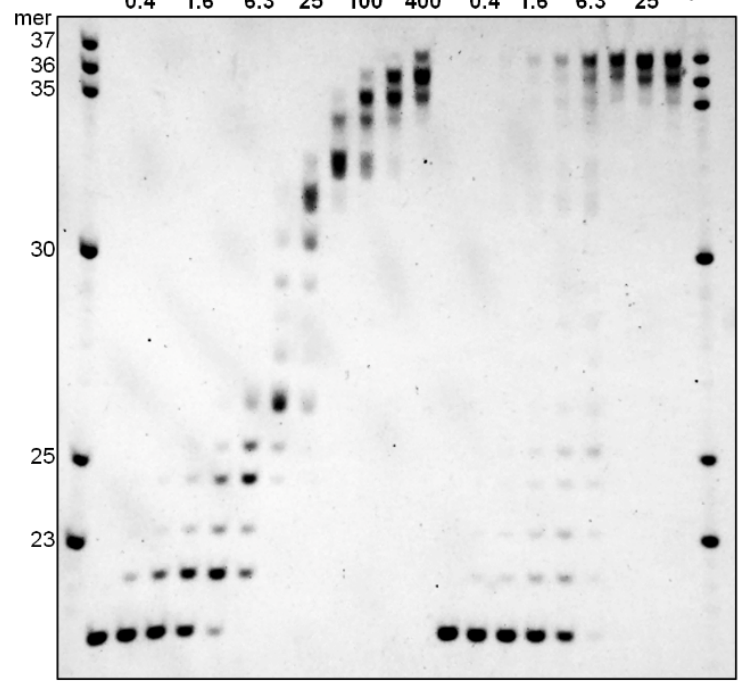

577

Figure 1

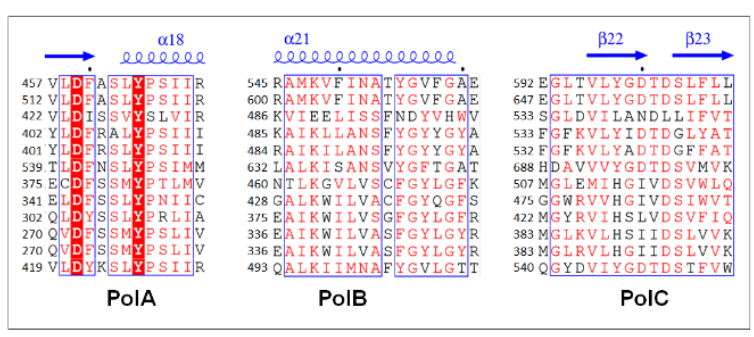

C 5' FAM-GTGACAGCATCTCATACTCCN (21) $3^{\prime}$
$3^{\prime}$ CACTGTCGTAGAGTATGAGGTCTCCGATTCCACTTT (36) 5'

$\mathrm{N}=\mathrm{C} \quad \mathrm{N}=\mathrm{G} \quad \mathrm{N}=\mathrm{T}$

Dpo2 2 Dpo1_ Dpo2 2 Dpo1 _ Dpo2 Dpo1 $25^{100} 4005{ }_{100}{ }_{25}{ }^{100} 4005{ }_{100}{ }_{25}{ }^{100}{ }_{4005}{ }^{25}{ }_{100}{ }^{0}$ (nM Pol)

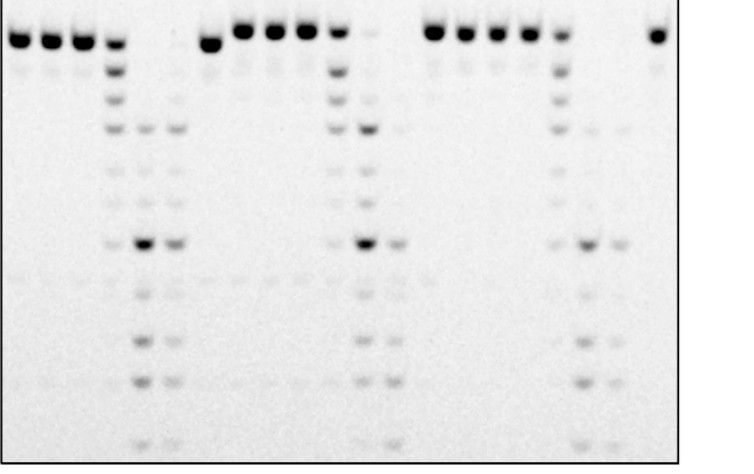


A novel specialized B-family DNA polymerase

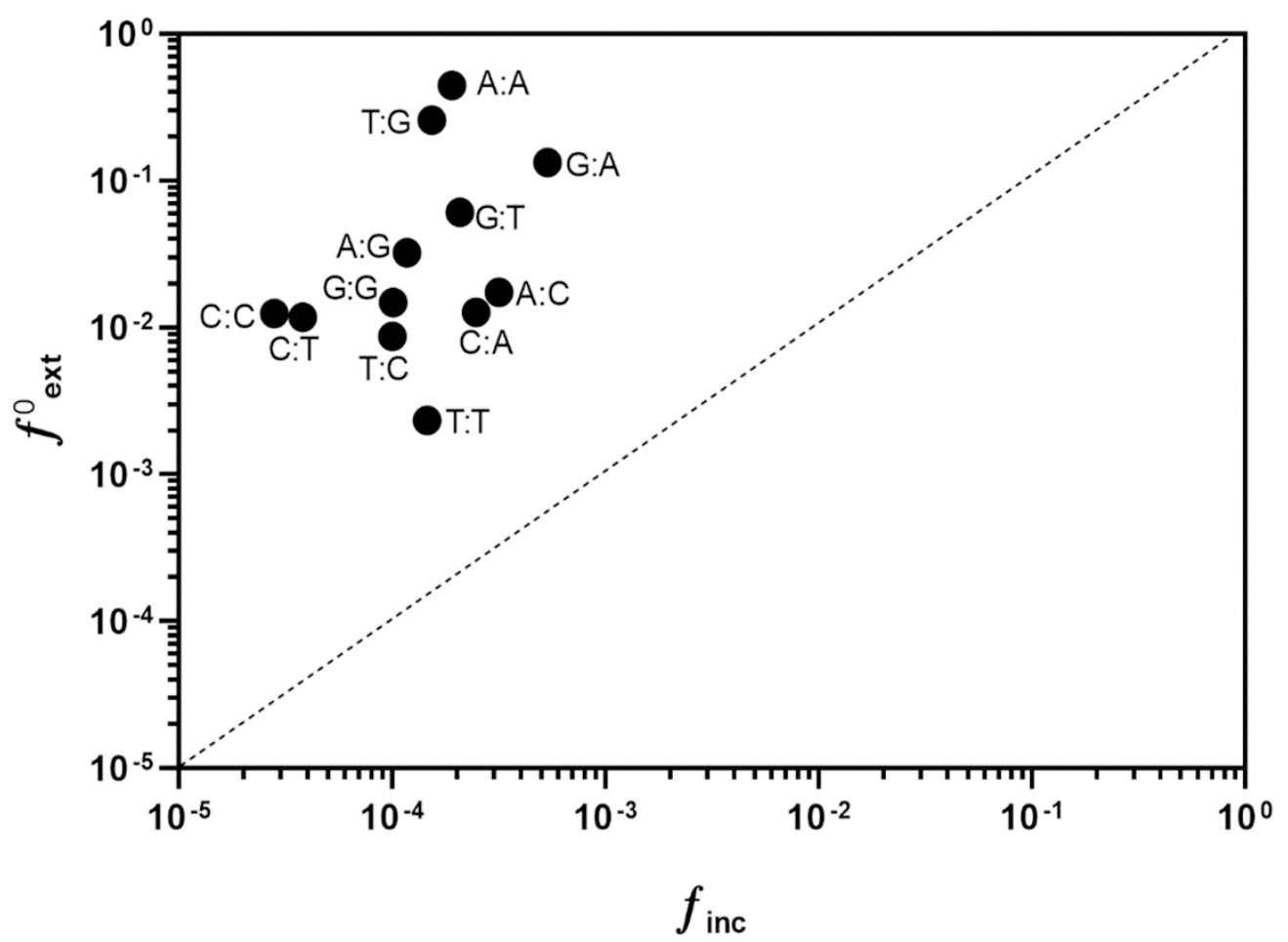

Figure 2 
A

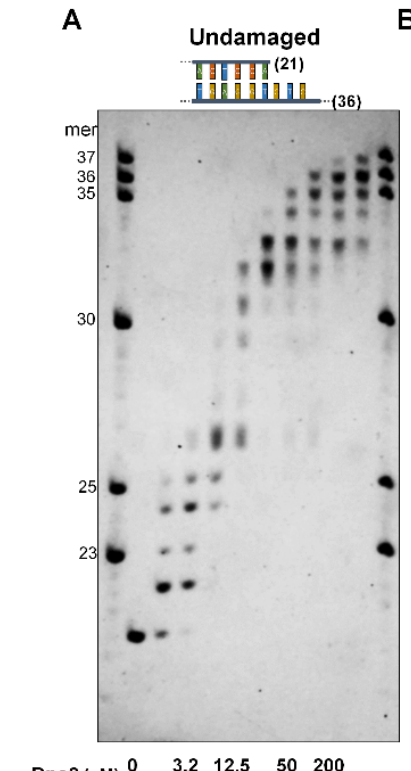

AP insertion AP extension $\mathrm{HH}^{(20)}$

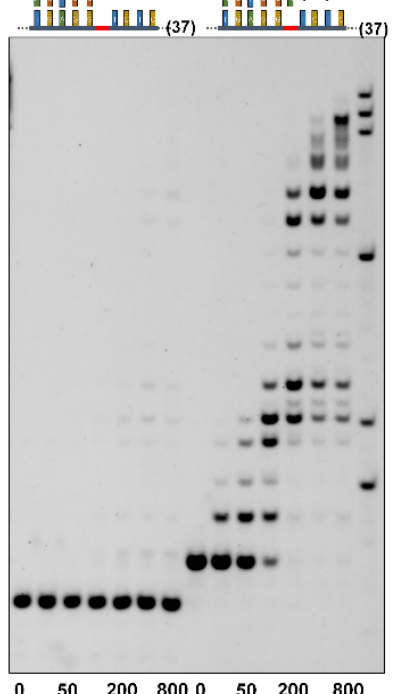

${ }_{25}{ }^{50}{ }_{100}^{200}{ }_{400}^{8000}{ }_{25}^{50}{ }_{100}^{200}{ }_{400}^{800}$

A novel specialized B-family DNA polymerase

c

CPD insertion CPD extension $D$ "TाI (19)

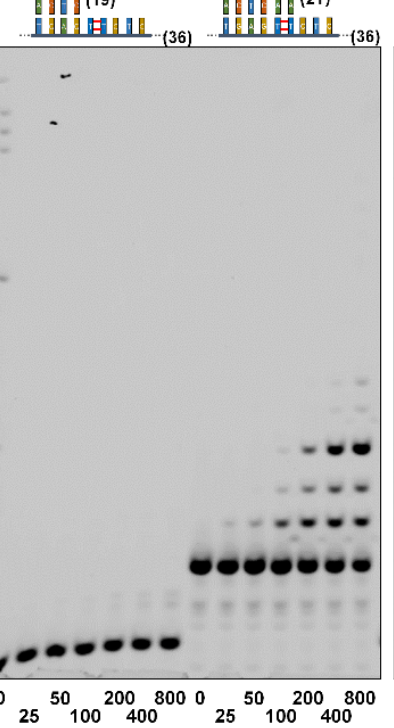

8-oxodG insertion 8-oxodG extension IIII (19)

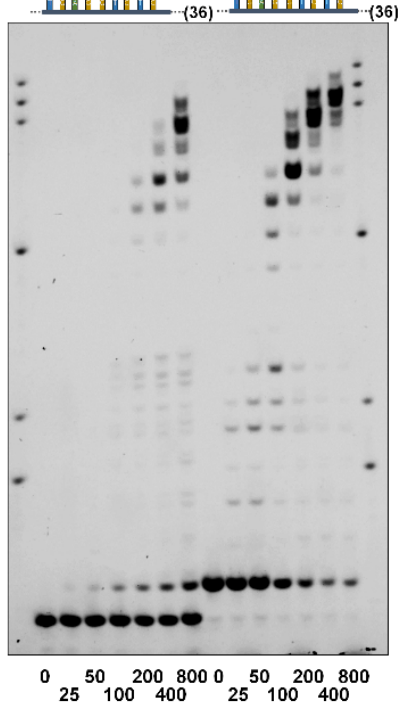

\section{$582 \quad$ Figure 3}


A novel specialized B-family DNA polymerase

B

A
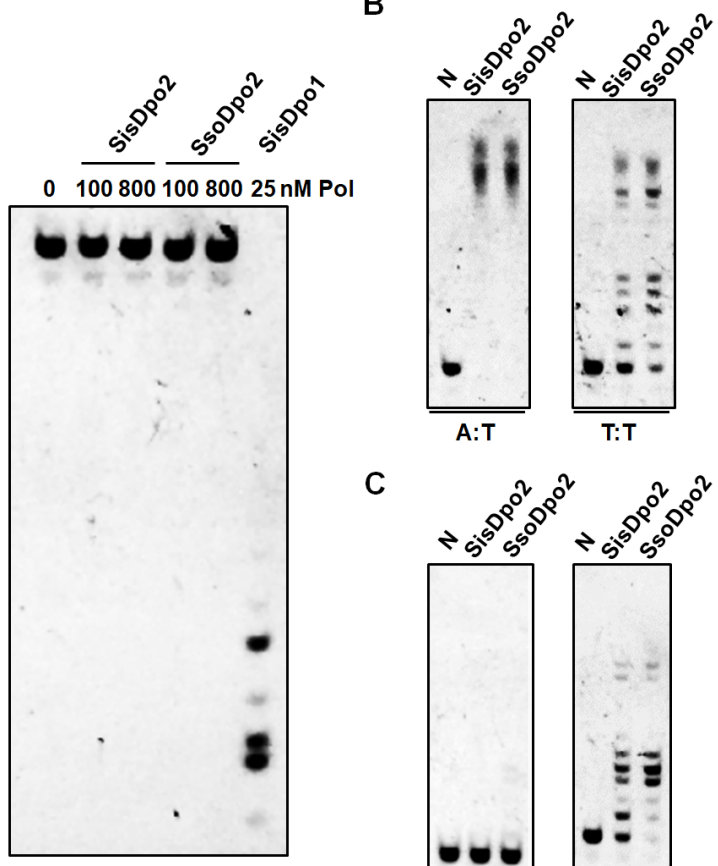

C

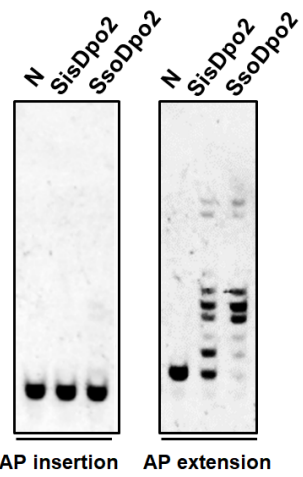

Figure 4 


\section{Supplementary Material}

\section{Supplementary Tables}

586 Supplementary Table S1. Oligonucleotides Used in This Study

\begin{tabular}{|c|c|c|}
\hline $\begin{array}{l}\text { Primer } \\
\text { strand }\end{array}$ & Sequence (5' to $\left.3^{\prime}\right)$ & Source \\
\hline $\mathrm{P} 1$ & 5' FAM-GTGACAGCATCTCATACTC & Genewiz \\
\hline $\mathrm{P} 2$ & 5' FAM-GTGACAGCATCTCATACTCC & Genewiz \\
\hline P3 & 5' FAM-GTGACAGCATCTCATACTCCA & Genewiz \\
\hline P3T & 5' FAM-GTGACAGCATCTCATACTCCT & Genewiz \\
\hline P3G & 5' FAM-GTGACAGCATCTCATACTCCG & Genewiz \\
\hline P3C & 5' FAM-GTGACAGCATCTCATACTCCC & Genewiz \\
\hline P2-CPD & 5' FAM-GTGACAGCATCTCATACTC & Genewiz \\
\hline P4-CPD & 5' FAM-GTGACAGCATCTCATACTCAA & Genewiz \\
\hline $\begin{array}{l}\text { Template } \\
\text { strand }\end{array}$ & Sequence (3' to $\left.5^{\prime}\right)$ & \\
\hline T1-A & 3' CACTGTCGTAGAGTATGAGGACTCCGATTCCACTTT & Genewiz \\
\hline T1 & 3' CACTGTCGTAGAGTATGAGGTCTCCGATTCCACTTT & Genewiz \\
\hline T1-G & 3' CACTGTCGTAGAGTATGAGGGCTCCGATTCCACTTT & Genewiz \\
\hline T1-G-A & 3' CACTGTCGTAGAGTATGAGGGATCCGATTCCACTTT & Genewiz \\
\hline T1-C & 3' CACTGTCGTAGAGTATGAGGCCTCCGATTCCACTTT & Genewiz \\
\hline T1-AP & 3' CACTGTCGTAGAGTATGAGGXTCTCCGATTCCACTTT & Genewiz \\
\hline T2-CPD & 3' CACTGTCGTAGAGTATGAGTTCTCCGATTCCACTTT & GeneLink \\
\hline T1-oxoG & 3' CACTGTCGTAGAGTATGAGoxoGTCTCCGATTCCACTTT & Sangon \\
\hline $\begin{array}{l}\text { Cloning } \\
\text { primers }\end{array}$ & Sequence (5' to $\left.3^{\prime}\right)$ & \\
\hline Dpo1-F & gaatgaggtgaagctcatatgAGTAAGCAACTTACCTTATTTGATATTCC & Tsingke \\
\hline Dpo1-R & ggccgcttgatcagcgtcgacATTATTCССТTTTССТССТGTGAA & Tsingke \\
\hline $\begin{array}{l}\text { SsoDpo2- } \\
\text { Ndel-F }\end{array}$ & GGCCACTcatatgCGAGAAATGGAGGAGTACGTAC & Tsingke \\
\hline $\begin{array}{l}\text { SsoDpo2- } \\
\text { Sall-R }\end{array}$ & ATTTgtcgacACACCTAGACATCACCTCTTCC & Tsingke \\
\hline
\end{tabular}


bioRxiv preprint doi: https://doi.org/10.1101/2021.09.10.459716; this version posted September 11, 2021. The copyright holder for this preprint (which was not certified by peer review) is the author/funder. All rights reserved. No reuse allowed without permission.

A novel specialized B-family DNA polymerase

587 TT represent a CPD dimmer and X denotes a synthetic abasic site. oxoG means an 8-oxodG site.

588

589 
590 Supplementary Table S2. DNA Substrates Used in This Study

\begin{tabular}{ll}
\hline Substrates & Sequence $\mathbf{~ ( 5 ' ~ t o ~} \mathbf{3}$ ' for top strand and $\mathbf{3}$ ' to $\mathbf{5}^{\prime}$ for bottom strand) \\
\hline P2-T1 & GTGACAGCATCTCATACTCC \\
& CACTGTCGTAGAGTATGAGGTCTCCGATTCCACTTT \\
\hline P2-T1A & GTGACAGCATCTCATACTCC \\
& CACTGTCGTAGAGTATGAGGACTCCGATTCCACTTT \\
\hline P2-T1G & GTGACAGCATCTCATACTCC \\
& CACTGTCGTAGAGTATGAGGGCTCCGATTCCACTTT \\
\hline
\end{tabular}

P2-T1G-A GTGACAGCATCTCATACTCC

CACTGTCGTAGAGTATGAGGGATCCGATTCCACTTT

P2-T1C GTGACAGCATCTCATACTCC

CACTGTCGTAGAGTATGAGGCCTCCGATTCCACTTT

\begin{tabular}{ll}
\hline P3-T1 & GTGACAGCATCTCATACTCCA \\
& CACTGTCGTAGAGTATGAGGTCTCCGATTCCACTTT \\
\hline P3-T1A & GTGACAGCATCTCATACTCCA \\
& CACTGTCGTAGAGTATGAGGACTCCGATTCCACTTT \\
\hline
\end{tabular}

P3-T1G GTGACAGCATCTCATACTCCA

CACTGTCGTAGAGTATGAGGGCTCCGATTCCACTTT

P3-T1C GTGACAGCATCTCATACTCCA

CACTGTCGTAGAGTATGAGGCCTCCGATTCCACTTT

\begin{tabular}{ll}
\hline P3T-T1 & GTGACAGCATCTCATACTCCT \\
& CACTGTCGTAGAGTATGAGGTCTCCGATTCCACTTT \\
\hline
\end{tabular}

P3T-T1A GTGACAGCATCTCATACTCCT

CACTGTCGTAGAGTATGAGGACTCCGATTCCACTTT

\begin{tabular}{ll}
\hline P3T-T1G & GTGACAGCATCTCATACTCCT \\
& CACTGTCGTAGAGTATGAGGGCTCCGATTCCACTTT
\end{tabular}

P3T-T1C GTGACAGCATCTCATACTCCT

CACTGTCGTAGAGTATGAGGCCTCCGATTCCACTTT

P3G-T1

GTGACAGCATCTCATACTCCG 
A novel specialized B-family DNA polymerase

\begin{tabular}{|c|c|}
\hline & CACTGTCGTAGAGTATGAGGTCTCCGATTCCACTTT \\
\hline \multirow[t]{2}{*}{ P3G-T1A } & GTGACAGCATCTCATACTCCG \\
\hline & CACTGTCGTAGAGTATGAGGACTCCGATTCCACTTT \\
\hline \multirow[t]{2}{*}{ P3G-T1G } & GTGACAGCATCTCATACTCCG \\
\hline & СACTGTCGTAGAGTATGAGGGCTCCGATTCCACTTT \\
\hline \multirow[t]{2}{*}{ P3G-T1C } & GTGACAGCATCTCATACTCCG \\
\hline & CACTGTCGTAGAGTATGAGGCCTCCGATTCCACTTT \\
\hline \multirow[t]{2}{*}{ P3C-T1 } & GTGACAGCATCTCATACTCCC \\
\hline & CACTGTCGTAGAGTATGAGGTCTCCGATTCCACTTT \\
\hline \multirow[t]{2}{*}{ P3C-T1A } & GTGACAGCATCTCATACTCCC \\
\hline & САCTGTCGTAGAGTATGAGGACTCCGATTCCACTTT \\
\hline \multirow[t]{2}{*}{ P3C-T1G } & GTGACAGCATCTCATACTCCC \\
\hline & САCTGTCGTAGAGTATGAGGGCTCCGATTCCACTTT \\
\hline
\end{tabular}

P3C-T1C GTGACAGCATCTCATACTCCC

CACTGTCGTAGAGTATGAGGCCTCCGATTCCACTTT

\begin{tabular}{ll}
\hline P2CPD-T2CPD & GTGACAGCATCTCATACTC \\
& CACTGTCGTAGAGTATGAGTTCTCCGATTCCACTTT
\end{tabular}

P4CPD-T2CPD GTGACAGCATCTCATACTCAA

CACTGTCGTAGAGTATGAGTTCTCCGATTCCACTTT

\begin{tabular}{ll}
\hline $\begin{array}{l}\text { P1-T1-oxoG (oxoG } \\
\text { insertion) }\end{array}$ & $\begin{array}{l}\text { GTGACAGCATCTCATACTC } \\
\text { CACTGTCGTAGAGTATGAGoxoGTCTCCGATTCCACTTT }\end{array}$ \\
\hline $\begin{array}{l}\text { P2-T1-oxoG (oxoG } \\
\text { extension) }\end{array}$ & $\begin{array}{l}\text { GTGACAGCATCTCATACTCC } \\
\text { CACTGTCGTAGAGTATGAGoxoGTCTCCGATTCCACTTT }\end{array}$ \\
\hline $\begin{array}{l}\text { P2-T1AP (AP } \\
\text { insertion) }\end{array}$ & $\begin{array}{l}\text { GTGACAGCATCTCATACTCC } \\
\text { CACTGTCGTAGAGTATGAGGXTCCGATTCCACTTT }\end{array}$ \\
\hline $\begin{array}{l}\text { P3-T1AP (AP } \\
\text { extension) }\end{array}$ & GTGACAGCATCTCATACTCCA \\
\hline
\end{tabular}

Each substrate is annotated with names of its primer and template and the assay in which the substrate is to be used is given in the parentheses. a. For dG incorporation on P2-T1G, there is a propensity for strand slippage mechanism to occur, leading to the pairing of the incoming nucleotide (dG) and the 5' flanking template base $(\mathrm{dC})$, which is a correct base pairing instead of a mismatched base pair. To avoid that, the P2-T1G-A substrate, in which the 5' dG was changed to dA, was used instead. TT represent a CPD dimmer and $X$ denotes a synthetic abasic site. oxoG means an 8-oxodG site. 
bioRxiv preprint doi: https://doi.org/10.1101/2021.09.10.459716; this version posted September 11, 2021. The copyright holder for this preprint (which was not certified by peer review) is the author/funder. All rights reserved. No reuse allowed without permission.

\section{A novel specialized B-family DNA polymerase}
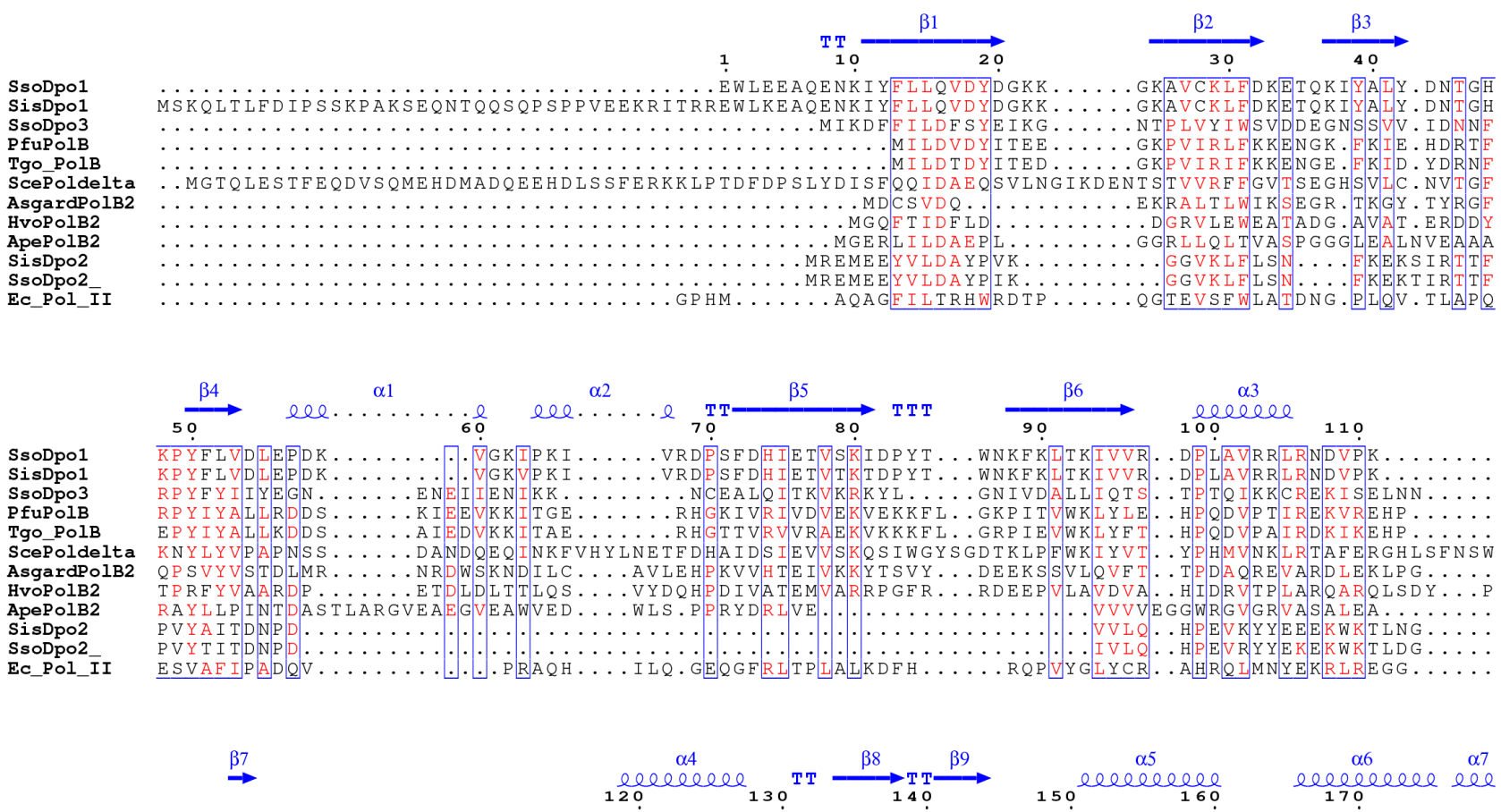

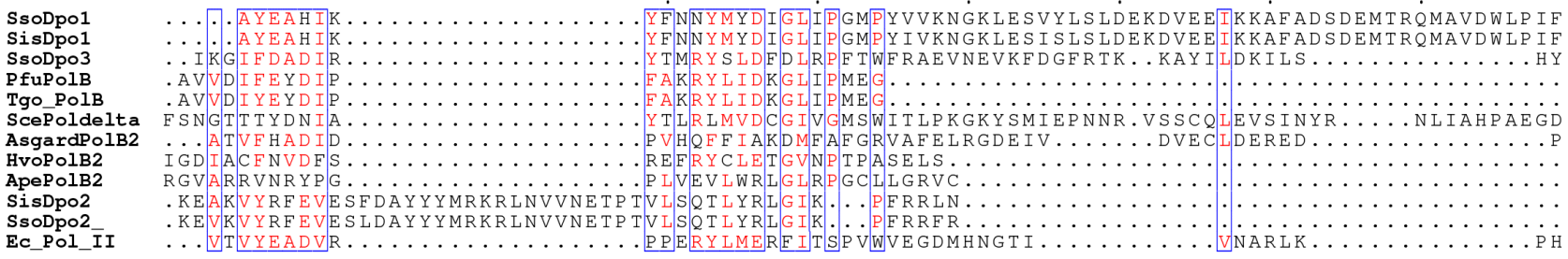

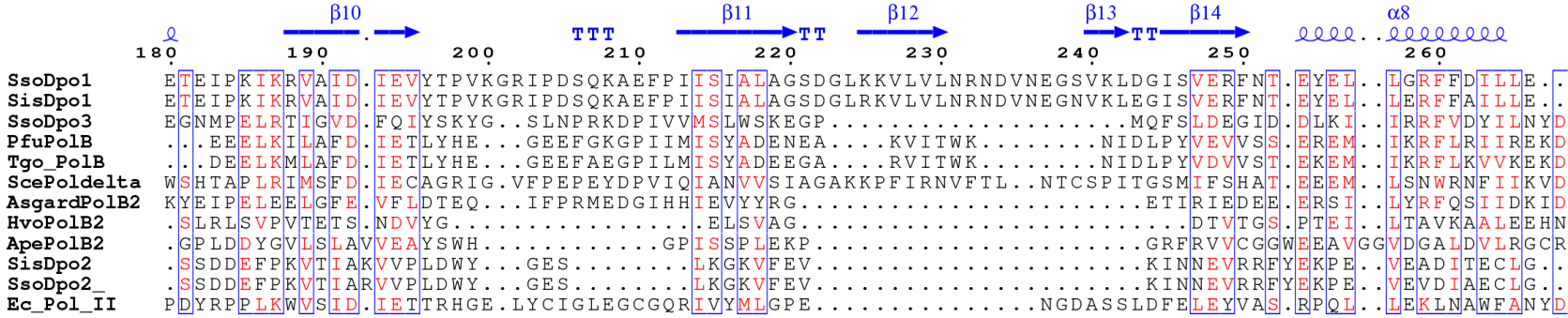
Exo I

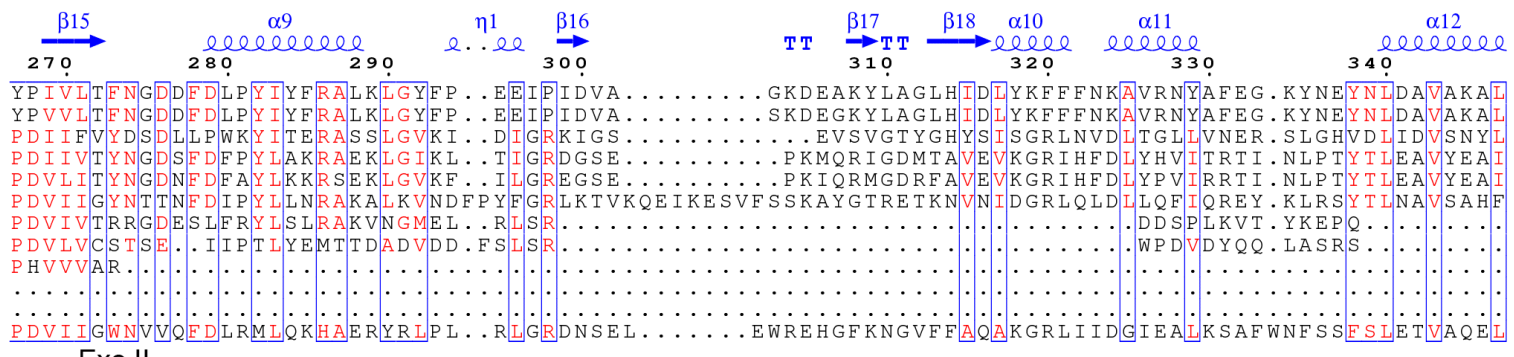
Exo II

SsoDpo1
SisDpo1
SsoDpo3
PfuPolB
Tgo_PolB
ScePoldelta
AsgardPolB2
HvoPolB2
ApePolB2
SisDpo2
SsODpo2
Ec_Pol_II

Ec_Pol_II 
bioRxiv preprint doi: https://doi.org/10.1101/2021.09.10.459716; this version posted September 11, 2021. The copyright holder for this preprint (which was not certified by peer review) is the author/funder. All rights reserved. No reuse allowed without permission.

\section{A novel specialized B-family DNA polymerase}
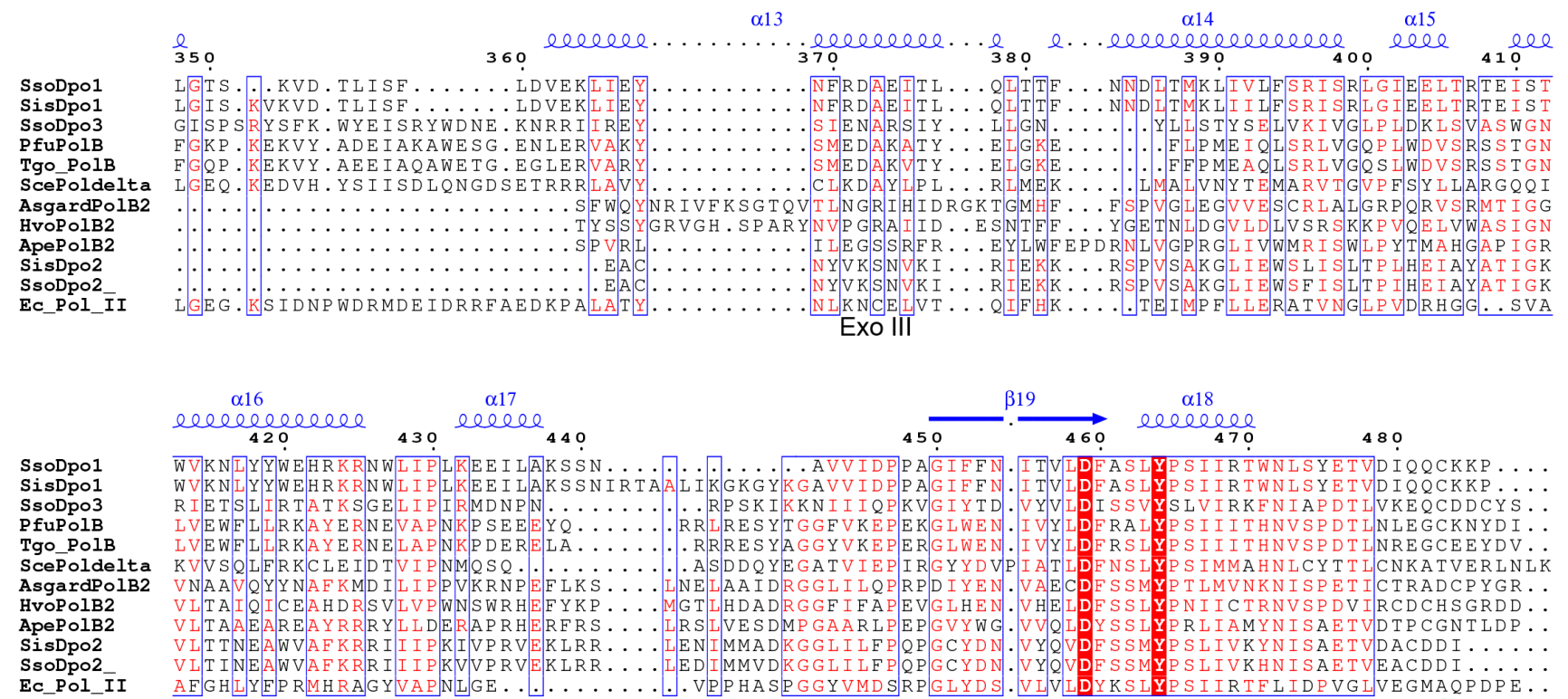

480

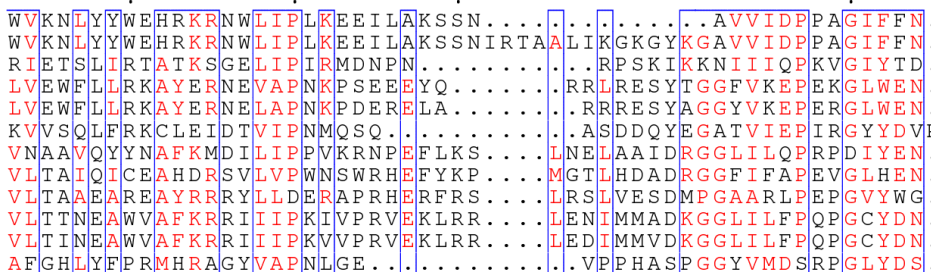
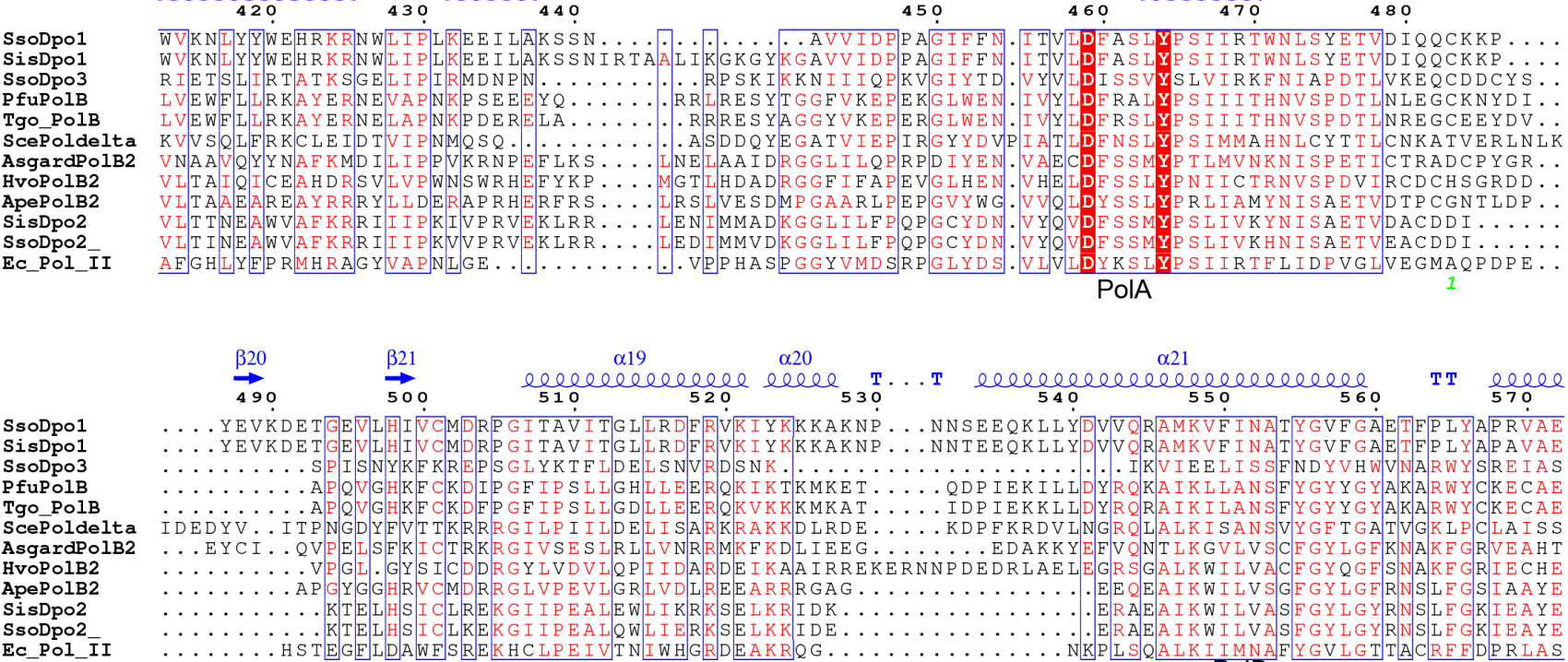
$\stackrel{\beta 20}{\rightarrow 490} \quad \overrightarrow{500}$
$\alpha 19$
$\alpha 20$
$\alpha 21$ .... YEVKDETREVILATI

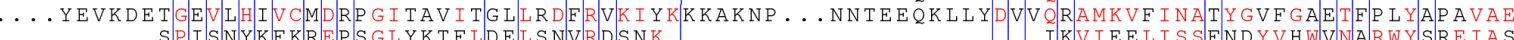

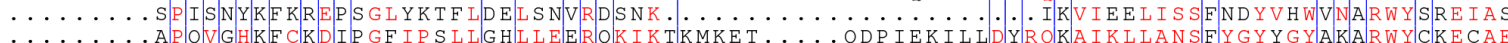

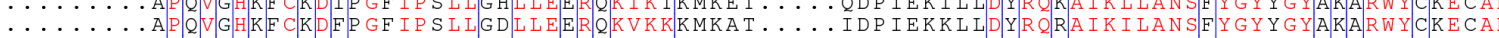

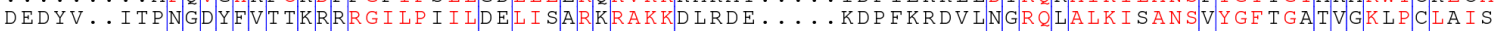

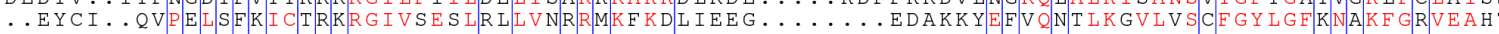

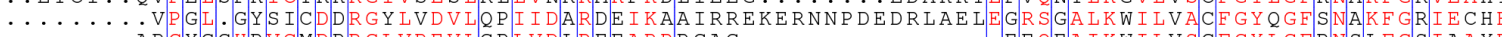

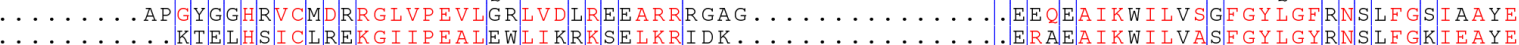

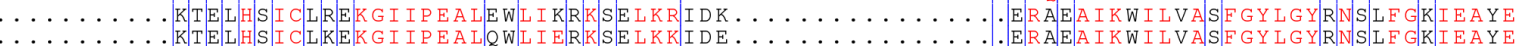

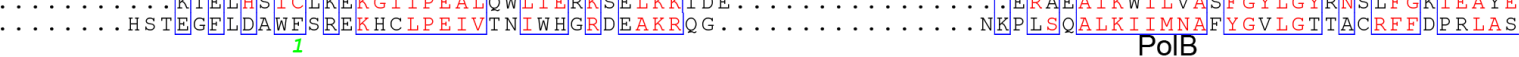

SsoDpo1
SisDpo1
SsoDpo3
PfuPolB
Tgo_PolB
ScePoldelta
AsgardPolB2
HvoPolB2
ApePolB2
SisDpo2
SsoDpo2
Ec_Pol_II

$\alpha 22$
eceelecelecee
580 SVTALGRYVITS STRKKARE. AFDEFSNEIIRFIIDLIKS.

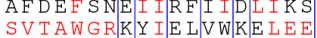

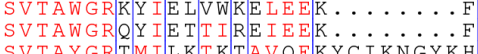

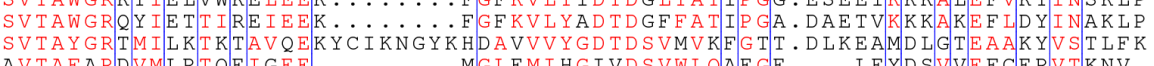

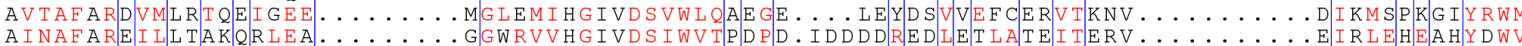

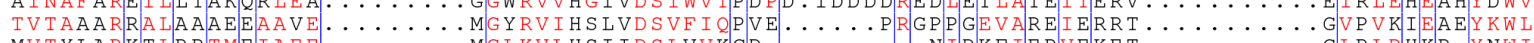

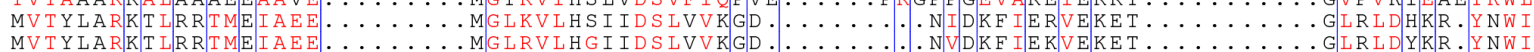
SITMRGHQIMRQTKALIEA.........

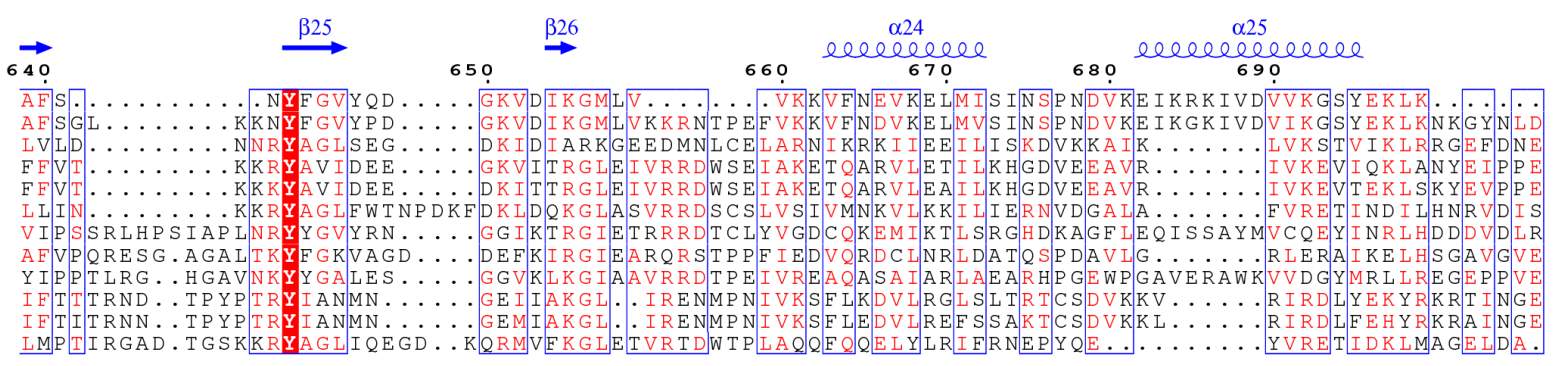


A novel specialized B-family DNA polymerase
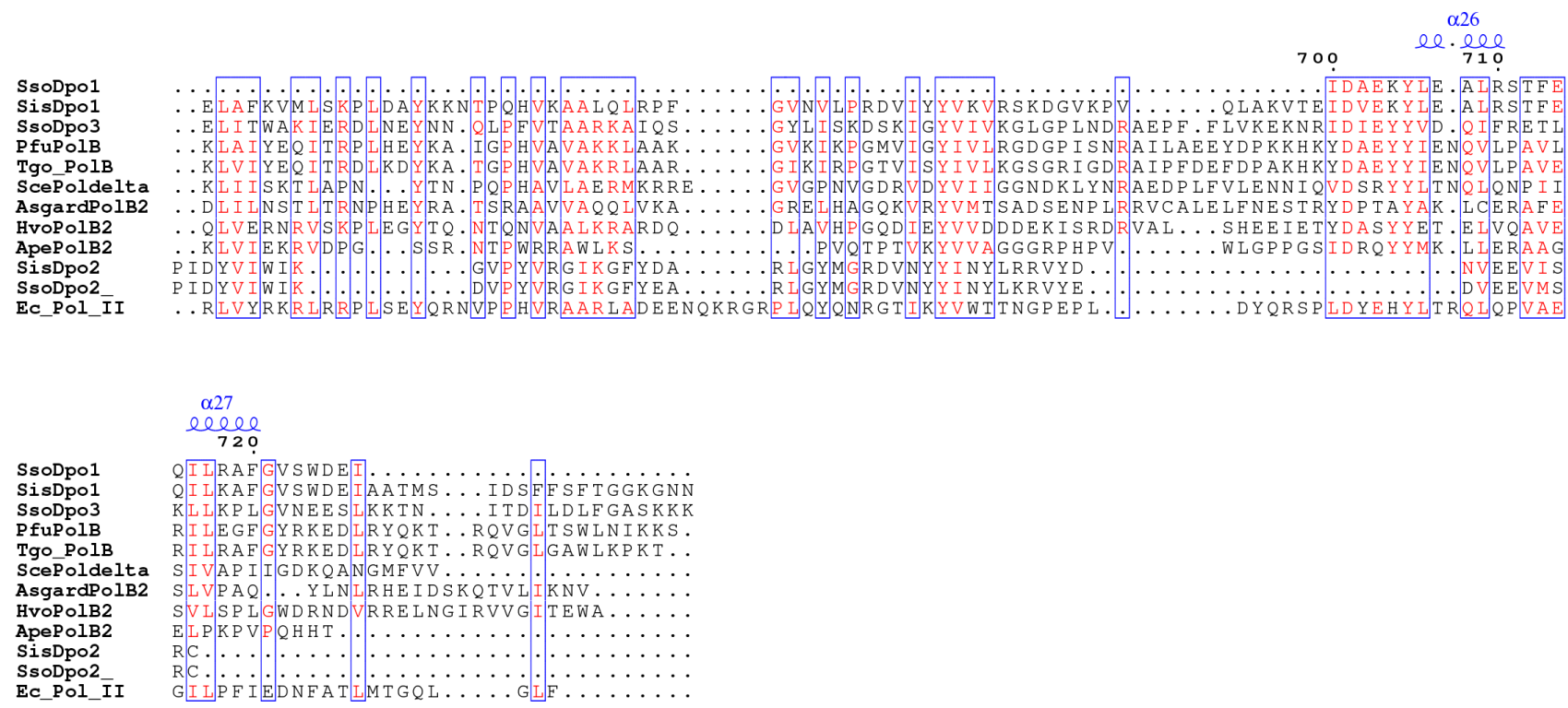

\section{1 \\ Supplementary Figure S1. Sequence aligment of a selelcted set of B-family DNA} polymerases

603 B-family DNA Polymerases employed for the analysis include SsoDpo1, S. solfataricus Dpo1; 604 SisDpo1, S. islandicus Dpo1; SsoDpo3, S. solfataricus Dpo3; PfuPolB, Pyrococcus furiosus 605 PolB; Tgo_PolB, Thermococcus gorgonarius PolB; ScePoldelta, the catalytic subunit of 606 Saccharomyces cerevisiae Pol $\delta$; AsgardPolB2, Candidatus Thorarchaeota archaeon PolB2; 607 HvoPolB2, Haloferax volcanii PolB2; ApePolB2, Aeropyrum pernix PolB2, and Ec_Pol_II, E. 608 coli Pol II. Structures of SsoDpol (1S5J) was used as the templates for the structure-based 609 sequence alignment. The secondary structural elements shown above the sequences were 610 retrieved from the structure file of SsoDpo1 (1S5J). 
A

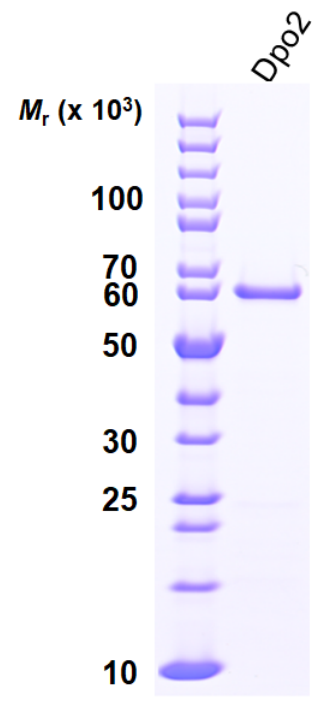

B

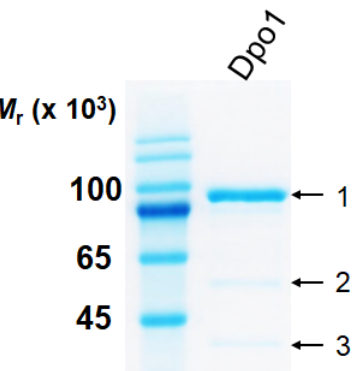

35

25

10

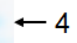

613

614 Supplementary Figure S2. SDS-PAGE analysis of purified Dpo2 and Dpo1 proteins from 615 the native host

616 (A) Dpo2 with a theoretical size of 64,927 daltons. (B) Dpo1 with a theoretical size of 101,205 617 daltons. Mass spectrometry confirmed that the band 1 corresponsding to a size of 100,000 was

618 PolB1, as were two smaller species of $\sim 60,000$ (2) and $\sim 40,000$ (3), which were presumably 619 resulted from Dpo1 degradation. The smallest species (4) were identified as Dpo1 degredation 620 and PBP1 (SiRe_1861), which is probably part of the Dpo1 holoenzyme, as have been shown for 621 SsoDpo1 [8]. 


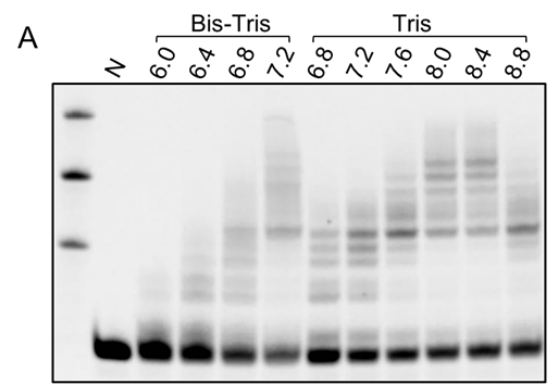

B

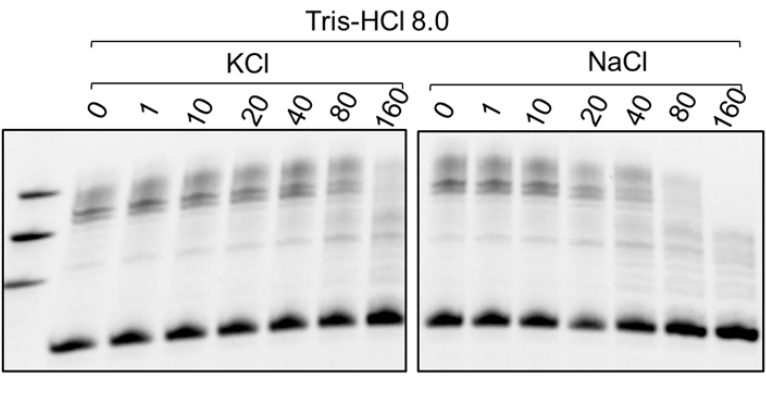

C

D

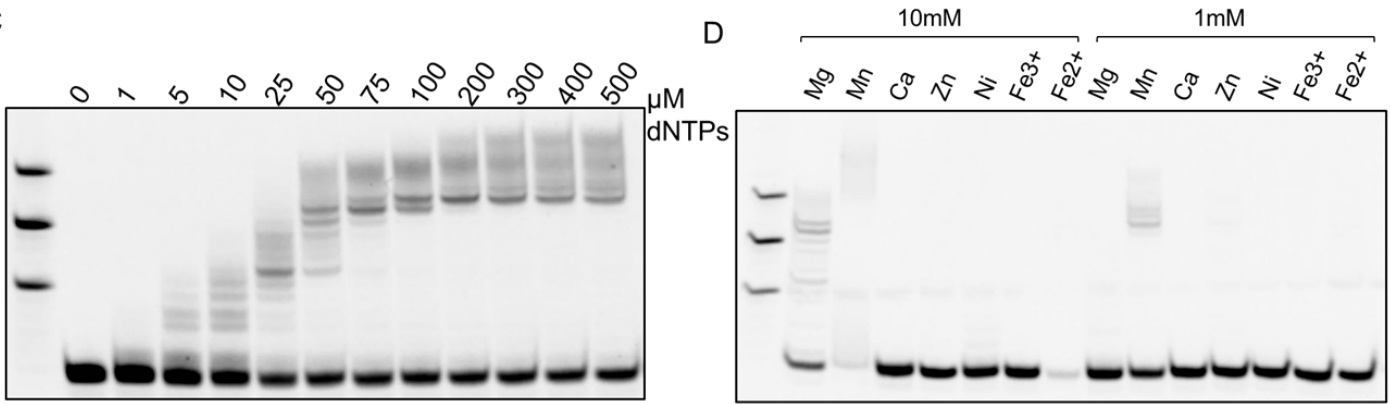

E

$\mathrm{F}$

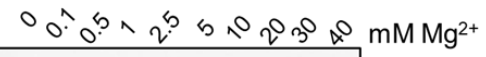

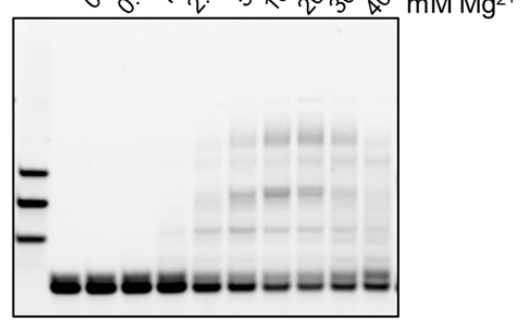

Supplementary Figure S3. Optimization of the reaction condition

DNA substrates were the same as shown in Figure 1. Reactions were set up with $37.5 \mathrm{nM}$ Dpo2 and $50 \mathrm{nM}$ substrates. (A) Optimization of the reaction $\mathrm{pH}$ at $60{ }^{\circ} \mathrm{C}$. N: no enzyme control. (B) Optimization of salt concentration at $60^{\circ} \mathrm{C}$ using the Tris- $\mathrm{HCl}$ buffer, $\mathrm{pH}$ 8.0. (C) Optimization of dNTP concentration, using Tris- $\mathrm{HCl} \mathrm{pH} 8.0$ buffer containing $40 \mathrm{mM} \mathrm{KCl}$ and $0.1 \mathrm{mg} / \mathrm{ml} \mathrm{BSA}$ at $60{ }^{\circ} \mathrm{C}$. (D) Metal ions-dependence of Dpo2. The reactions were carried out with Tris- $\mathrm{HCl} \mathrm{pH} 8.0$ containing $40 \mathrm{mM} \mathrm{KCl}$ and $0.1 \mathrm{mg} / \mathrm{ml} \mathrm{BSA}$ at $60{ }^{\circ} \mathrm{C} . \mathrm{Mg}^{2+}$ was used since some of the following analyses involved the use of multiple DNA Pol enzymes and a much higher physiological concentration of $\mathrm{Mg} 2+$ have been reported than other metal ions. (E) Determination of theoptimal reaction temperature using Tris- $\mathrm{HCl} \mathrm{pH} 8.0$ buffer containing $40 \mathrm{mM} \mathrm{KCl}$ and $0.1 \mathrm{mg} / \mathrm{ml} \mathrm{BSA}$ at indicated temperature. (F) Optimization of $\mathrm{Mg} 2+$ concentration. At last, the optimized buffer system for Dpo2 contains $50 \mathrm{mM}$ Tris-HCl pH 8.0, $40 \mathrm{mM} \mathrm{KCl}, 0.1 \mathrm{mg} / \mathrm{ml} \mathrm{BSA}, 10 \mathrm{mM} \mathrm{MgCl} 2$, $100 \mu \mathrm{M}$ dNTPs. In the single nucleotide incorporation assay and kinetics analysis, the dNTPs mixtures were omitted and single dNTP with indicated concentrations was instead used. 
A novel specialized B-family DNA polymerase

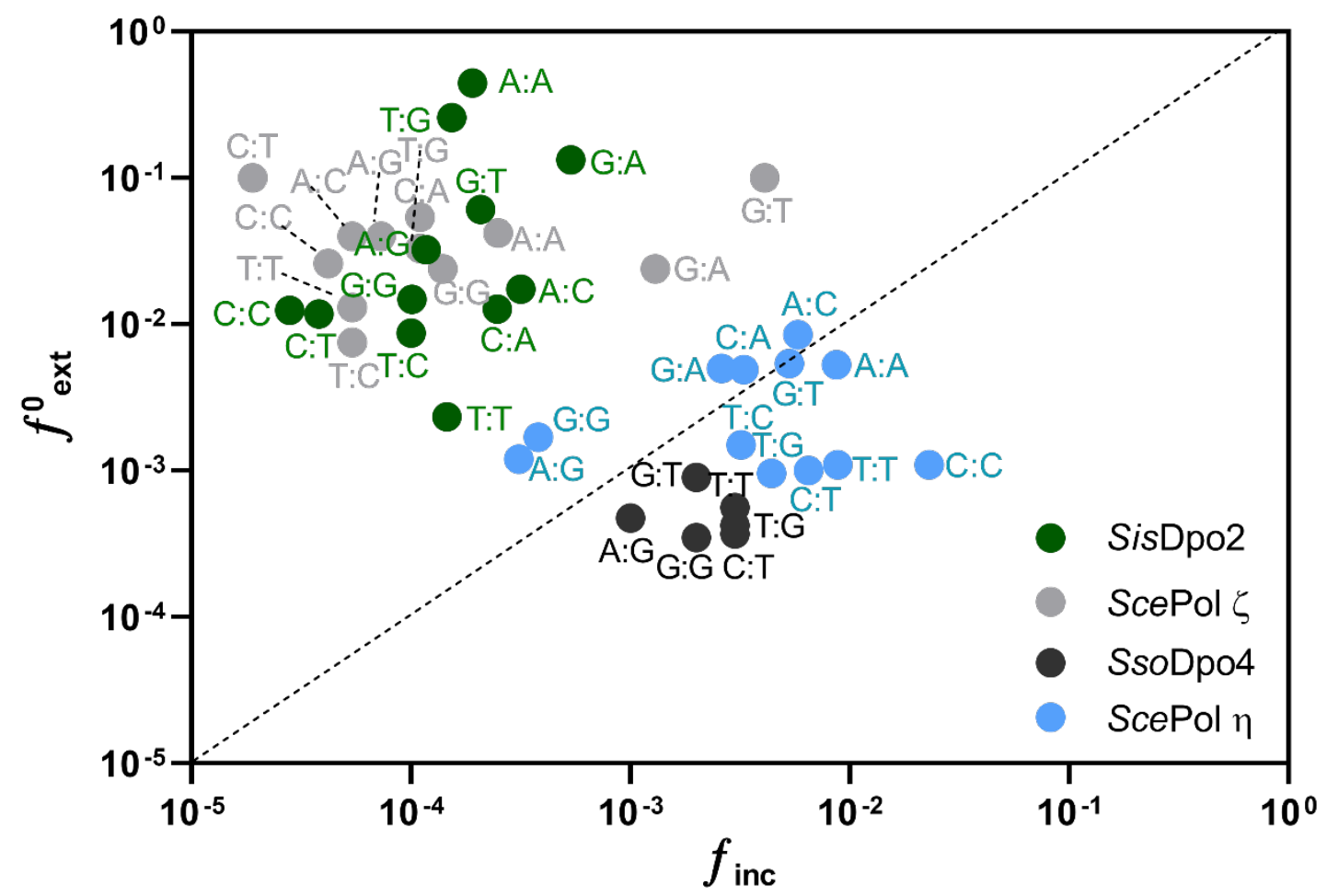

639

640 Supplementary Figure S4. A comparison of mismatch extension ability of extender and non641 extender DNA polymerases

642 The finc and f0ext values of Saccharolobus solfataricus Dpo4 (SsoDpo4), Saccharomyces 643 cerevisiae Pol $\zeta$ (ScePol $\zeta$ ) and S. cerevisiae Pol $\eta$ (ScePol $\eta$ ) are retrieved from [56], [29] and 644 [57] respectively. 
646

A

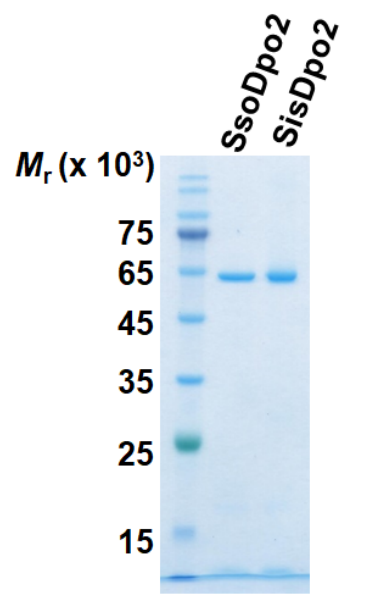

B

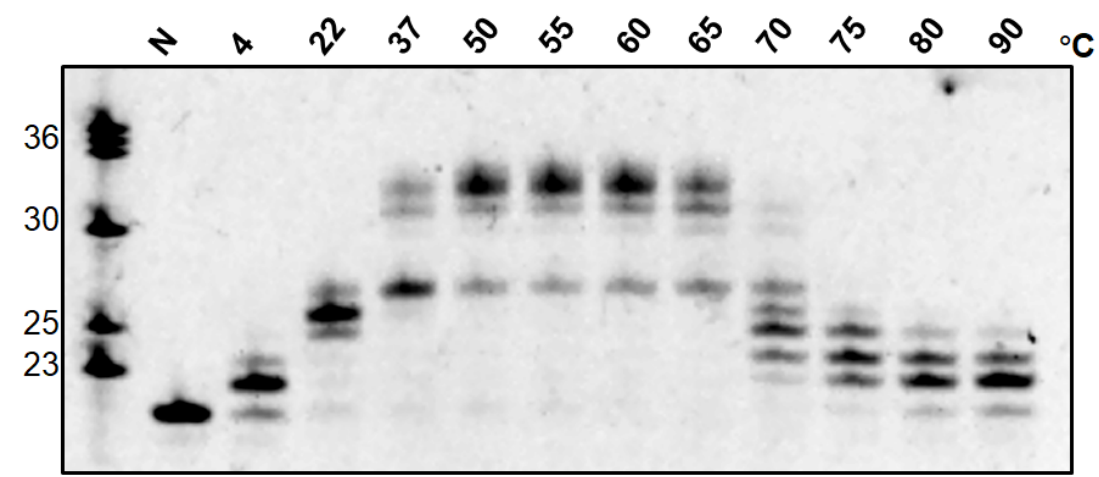

649 (A) SDS-PAGE analysis of purified SisDpo2 and SsoDpo2 proteins. SisDpo2, Sulfolobus 650 islandicus Dpo2. SsoDpo2, S. solfataricus Dpo2. Both proteins were expressed in the S. 651 islandicus host. (B) the optimal temperature of SsoDpo2. The reaction contains 17.5 nM SsoDpo2 652 protein and $50 \mathrm{nM}$ substrate used in Fig 1B, in the presence of $100 \mu \mathrm{M}$ dNTPs. The experiment 653 was carried out at the temperature indicated above each lane for $5 \mathrm{~min}$. 
A novel specialized B-family DNA polymerase

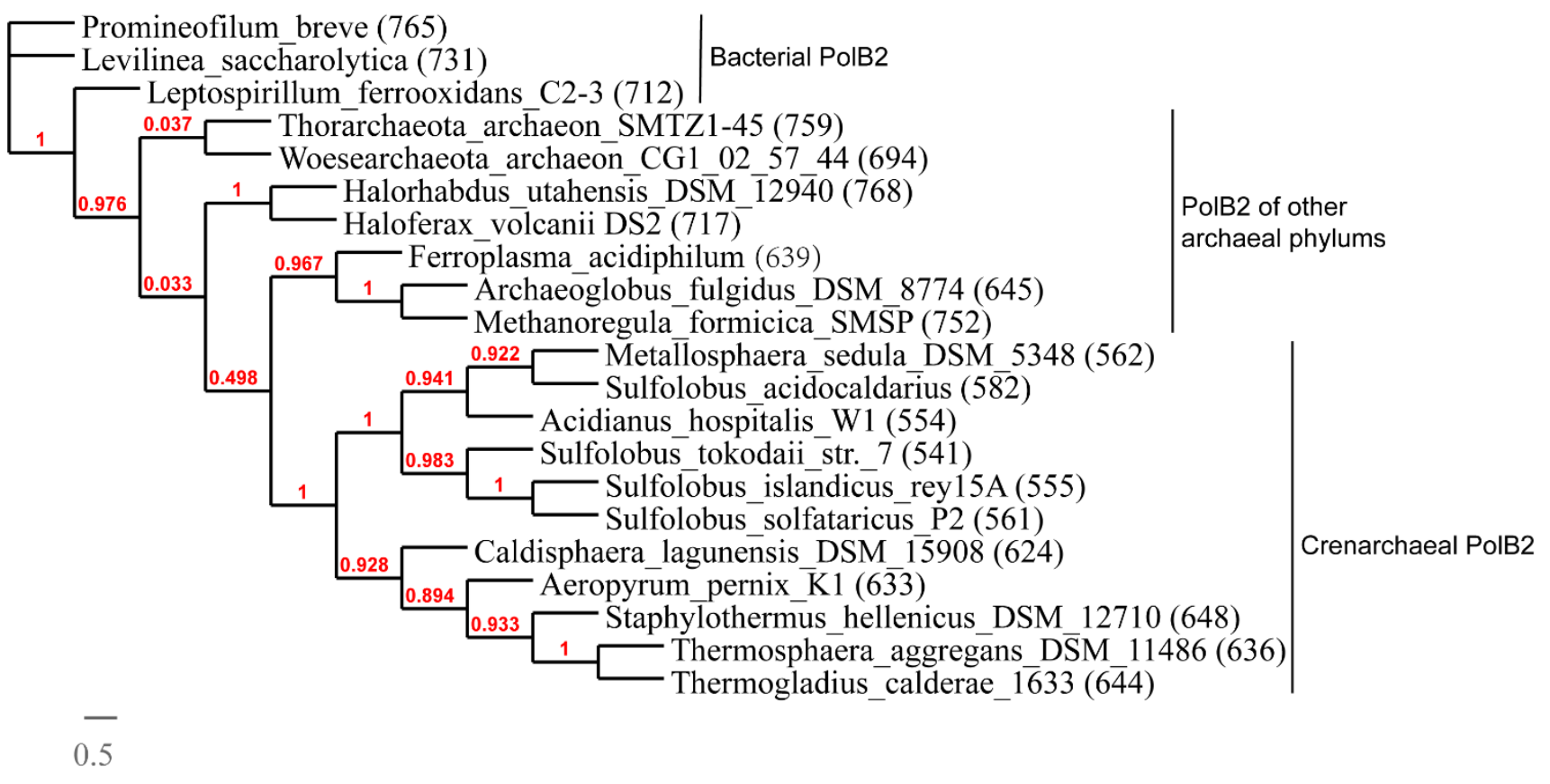

\section{Supplementary Figure S6. The phylogeny of PolB2 proteins}

657 The phylogenetic tree was constructed using sequences of PolB2s extracted from NCBI and the 658 analysis was performed on the Phylogeny.fr platform [58]. The size of each PolB2 was indicated 659 by the numbers in parentheses (aa). 
A novel specialized B-family DNA polymerase

\section{References}

662

663

664

665

666

667

668

669

[1] J. Yan, T.R. Beattie, A.L. Rojas, K. Schermerhorn, T. Gristwood, J.C. Trinidad, S.V. Albers, P. Roversi, A.F. Gardner, N.G.A. Abrescia, and S.D. Bell, Identification and characterization of a heterotrimeric archaeal DNA polymerase holoenzyme. Nat Commun 8 (2017) 15075.

[2] J. Trincao, R.E. Johnson, W.T. Wolfle, C.R. Escalante, S. Prakash, L. Prakash, and A.K. Aggarwal, Dpo4 is hindered in extending a G.T mismatch by a reverse wobble. Nat Struct Mol Biol 11 (2004) 457-62.

670

671

672

[3] R.E. Johnson, M.T. Washington, L. Haracska, S. Prakash, and L. Prakash, Eukaryotic polymerases iota and zeta act sequentially to bypass DNA lesions. Nature 406 (2000) 1015-9.

[4] M.T. Washington, R.E. Johnson, S. Prakash, and L. Prakash, Mismatch extension ability of yeast and human DNA polymerase eta. J Biol Chem 276 (2001) 2263-6.
[5] A. Dereeper, V. Guignon, G. Blanc, S. Audic, S. Buffet, F. Chevenet, J.F. Dufayard, S.
Guindon, V. Lefort, M. Lescot, J.M. Claverie, and O. Gascuel, Phylogeny.fr: robust 